\title{
Human Delta Like 1-Expressing Human Mesenchymal Stem Cells Promote Human T Cell Development and Antigen-Specific Response in Humanized NOD/SCID/IL-2Rgnull (NSG) Mice
}

Ki-Young Lee ( $\nabla$ thylee@skku.edu )

Sungkyunkwan University

Do Hee Kwon

Sungkyunkwan University

Jae Berm Park

Sungkyunkwan University

Joo Sang Lee

Sungkyunkwan University

Sung Joo Kim

Sungkyunkwan University

Bongkum Choi

Sungkyunkwan University

\section{Research Article}

Keywords: Humanized mice, Mesenchymal stem cells (MSCs), Delta-like 1 (DIk1), CD34+ cord blood (CB) stem cells, Epstein-Barr virus (EBV)

Posted Date: March 2nd, 2021

DOI: https://doi.org/10.21203/rs.3.rs-253268/v1

License: (c) (1) This work is licensed under a Creative Commons Attribution 4.0 International License. Read Full License 
Title:

\section{Human delta like 1-expressing human mesenchymal stem cells promote human $T$ cell development and antigen-specific response in humanized NOD/SCID/IL- $2 \mathrm{R} \gamma^{\text {null }}$ (NSG) mice}

Do Hee Kwon ${ }^{1}$, Jae Berm Park ${ }^{2,3}$, Joo Sang Lee ${ }^{4,5}$, Sung Joo Kim²,6, Bongkum Choi ${ }^{6,7,8}$, Ki-Young Lee L $^{1,3,5,8}$

${ }^{1}$ Department of Immunology and Samsung Biomedical Research Institute, Sungkyunkwan University School of Medicine, Suwon-Si, Kyonggi-Do 440-746, Korea.

${ }^{2}$ Department of Surgery, Samsung Medical Center, Sungkyunkwan University School of Medicine, Seoul, Republic of Korea.

${ }^{3}$ Department of Health Sciences and Technology, Samsung Advanced Institute for Health Sciences \& Technology, Samsung Medical Center, Sungkyunkwan University, Seoul, Republic of Korea.

${ }^{4}$ Department of Precision medicine, Sungkyunkwan University School of Medicine, Suwon-Si, Kyonggi-Do 440-746, Korea.

${ }^{5}$ Single Cell Network Research Center, Sungkyunkwan University School of Medicine, Suwon 16419, Republic of Korea

${ }^{6}$ GenNBio, Inc., Seoul, Republic of Korea.

${ }^{7}$ Department of Medicine, Sungkyunkwan University School of Medicine, Suwon-Si, Kyonggi-Do 440-746, Korea

${ }^{8}$ Corresponding Author: Ki-Young Lee, Department of Immunology and Samsung Biomedical Research Institute, Sungkyunkwan University School of Medicine, 2066 Seobu-ro, Jangan-gu, Suwon, Gyeonggi-do, 16419 Korea. Tel: +82-31-299-6225, Fax: +82-31-299-6229, E-mail: thylee@skku.edu; Bongkum Choi, Department of Medicine, 
Sungkyunkwan University School of Medicine, 2066 Seobu-ro, Jangan-gu, Suwon, Gyeonggi-do, 16419 Korea. Tel: +82-2-3410-7308, E-mail: choi79@skku.edu.

\section{Declarations}

Conflict of Interest. The authors declare they have no conflict of interest.

\section{Funding}

This work was partially supported by the National Research Foundation of Korea (NRF) Grants funded by the Korean Government (NRF-2018R1D1A1B07042470, NRF2020R1A2C2007652), Korea Basic Science Institute (National research Facilities and Equipment Center) grant funded by the Ministry of Education (2020R1A6C101A191), Ministry of Science ICT and Future Planning (MSIP) funded by the Korean Government (NRF-2016R1A5A2945889), by Ministry of Trade, Industry and Energy (MOTIE, 20012378), and by the Korea Health Technology R\&D Project through the Korea Health Industry Development Institute (KHIDI, HI20C0056).

\section{Data Availability}

The data that support the findings of this study are available upon request from the corresponding author

\section{Authorship Contribution}

DHK and BC generated, analyzed humanized mice, performed experiments. BC, JBK, JSL, SJK, K-YL designed the study and analyzed data. BC and K-YL wrote the manuscript. All authors critically reviewed the manuscript. 


\begin{abstract}
Human delta-like $1(\mathrm{hDlk} 1)$ is known to be able to regulate cell fate decisions during hematopoiesis. Mesenchymal stem cells (MSCs) are known to exhibit potent immunomodulatory roles in a variety of diseases. Herein, we investigated in vivo functions of hDlkl1 ${ }^{-h M S C s}$ and $\mathrm{hDlk1} 1^{+} \mathrm{hMSCs}$ in $\mathrm{T}$ cell development and $\mathrm{T}$ cell response to viral infection in humanized NOD/SCID/IL-2R $\gamma^{\text {null }}$ (NSG) mice. Co-injection of hDlk1 ${ }^{-h M S C}$ with hCD34 ${ }^{+}$cord blood (CB) cells into the liver of NSG mice markedly suppressed the development of human T cells. In contrast, co-injection of $\mathrm{hDlk} 1^{+} \mathrm{hMSC}$ with hCD $34^{+} \mathrm{CB}$ cells into the liver of NSG dramatically promoted the development of human T cells. Human T cells developed in humanized NSG mice represent markedly diverse in terms of TCR V $\beta$ usages, functionally active, and the restriction to human MHC molecules. Upon challenge with Epstein-Barr virus (EBV), EBV-specific hCD8 ${ }^{+} \mathrm{T}$ cells in humanized NSG mic were effectively mounted with phenotypically activated T cells presented as $\mathrm{hCD} 45^{+} \mathrm{hCD} 3^{+} \mathrm{hCD} 8^{+} \mathrm{hCD} 45 \mathrm{RO}^{+} \mathrm{hHLA}-\mathrm{DR}^{+} \mathrm{T}$ cells, suggesting that antigen-specific T cell response was induced in the humanized NSG mice. Taken together, our data suggest that the hDlk1-expressing MSCs can effectively promote the development of human $\mathrm{T}$ cells and immune response to exogenous antigen in humanized NSG mice. Thus, the humanized NSG model might have potential advantages for the development of therapeutics targeting infectious diseases in the future.
\end{abstract}

Keywords: Humanized mice, Mesenchymal stem cells (MSCs), Delta-like 1 (Dlk1), $\mathrm{CD}_{3}{ }^{+}$cord blood $(\mathrm{CB})$ stem cells, Epstein-Barr virus (EBV). 


\section{Introduction}

Humanized mice are valuable pre-clinical tools for developing new therapeutics and for studying human immune responses to infections by pathogens, development of human immune cells, and so on [1-10]. More than 20 years after the first successful engraftment of human leukocytes and hematopoietic organs into mice [11], many different humanized mice have been reported and used for a variety of purposes [1-11]. Recent advances in humanized mice have been focusing on methods for generating humanized mice with at least two purposes: 1) to make it simple to generate humanized mice; and 2) to make it efficacious to guarantee successful reconstitution of human immune cells without any graft-versus-host disease (GVHD) when grafting human cells in mice. As part of these efforts, many laboratories have developed new methodologies to develop humanized mice, including human fetal thymic and liver tissues (SCID-hu thy-liv mice)-engrafted humanized mice [5] and intravenous injected humanized mice [12]. We have recently reported that intrahepatic injection of $\mathrm{CD} 34^{+}$human (h) cord blood (CB) cells to conditioned newborn mice can successfully induce reconstitution of human immune cells in NOD/SCID/IL-2R $\gamma^{\text {null }}$ (NSG) mice [8]. Compared to the generation of SCID-hu thyliv mice-engrafted humanized mice, generating humanized mice by intrahepatic injection is simple so that they could be applied to solve current scientific issues including the development of therapeutics targeting human diseases and academic interests related to cellular and molecular functions of immune responses.

Mesenchymal stem cells (MSCs) have multi-potent effects and functions in immunomodulatory responses [13-16]. Co-transplantation of ex vivo-expanded human MSCs with hematopoietic stem cells can hasten hematopoietic recovery followed by bone marrow transplantation in animal models and humans [16-22]. In addition, MSCs have shown immuno-suppressive effects on T cells [23]. The production of HLA-G5 by MSCs can suppress T-cell proliferation and cytotoxicity induced by natural killer and T cells [24, 25]. Moreover, cell-to-cell contact between MSCs and activated T cells can induce IL-10 production essential to stimulate the release of soluble HLA-G5, resulting in systemic immunosuppressive effects on tumor growth [26, 27]. Nevertheless, whether MSCs might affect $\mathrm{T}$ cell development and generation in an in vivo system remains unclear. $\mathrm{T}$ cell 
development and generation in vivo are affected by a variety of environmental systems including cells, soluble mediators, and receptor-ligand interactions [28-31]. Among them, Notch signaling plays a key role for the decision of cell fate during the developmental stage. It also functionally contributes to the commitment of T cell lineage [32-34]. In mammals, four different notch receptors (NOTCH1, NOTCH2, NOTCH3, and NOTCH4), have been identified. They can transduce intracellular signaling related to cell proliferation and differentiation [32]. Recent studies have shown that delta-like 1 homolog (Dlk1) can directly interact with NOTCH1 receptor and modulate cell fate determination, terminal differentiation, and proliferation [35-37]. However, whether Dlk1 is functionally associated with $\mathrm{T}$ cell development, especially in an in vivo system, has not been reported yet.

In this study, we tried to answer the following two questions: 1) Could Dlk1 regulate human $\mathrm{T}$ cell development in humanized mice? and 2) Could MSC-induced immunomodulatory effects, especially in T cell development and function, be regulated by Dlk1? To answer these questions, we utilized humanized NSG mice generated by intrahepatic injection with $\mathrm{hCD} 34^{+} \mathrm{CB}$ cells alone or together with hMSC or hMSC expressing Dlk1. We then assessed the development of human T cells. Additionally, we examined whether antigen-specific $\mathrm{T}$ cell response was mounted in humanized mice challenged with Epstein-Barr virus (EBV). Our data demonstrated that co-injection of hDlk1-expressing MSCs dramatically promoted the development of human T cells and that human $\mathrm{T}$ cells exhibited functionally active, diverse TCR V $\beta$ usages with active response to human MHC molecules. Upon challenge with $\mathrm{EBV}, \mathrm{EBV}$-specific $\mathrm{hCD} 8^{+} \mathrm{T}$ cells were effectively generated. These results suggest that Dlk1-expressing MSCs can functionally facilitate human $\mathrm{T}$ cell development in humanized NSG mice. The humanized mouse model developed in this study together with diverse humanized mouse model available could be used to study various immune diseases and viral diseases in the future. 


\section{Materials and Methods}

All experiments involving animals were approved by the Laboratory Animal Research Center (LARC) of the Samsung Biomedical Research Institute in Seoul, Korea and adhered to the ARVO Statement for the Use of Animals in Ophthalmic and Vision Research and the ARRIVE (Animal Research: Reporting of In Vivo Experiments) guidelines. The human protocol for the experiments with human materials was approved by the Institutional Review Boards of Samsung Medical Center (SMC) (IRB No.: 201009-060).

\section{Mice and human fetal liver tissue}

NOD/SCID/IL-2R $\gamma^{\text {null }}$ (NSG) mice were purchased from the Jackson Laboratory (Bar Harbor). All mice were bred as a homozygous line and maintained under specificpathogen-free (SPF) conditions in accordance with ethical guidelines for the care of mice at the Laboratory Animal Research Center (LARC) of the Samsung Biomedical Research Institute in Seoul, Korea. Human fetal liver tissues of gestational age 17 to 22 weeks were obtained from the Samsung Medical Center (SMC). Informed, written consent was acquired from the patients or legal guardian (IRB No.: 2010-09-060).

\section{Isolation of human fetal liver-derived mesenchymal stem cells (hFL-MSCs)}

Human fetal liver tissues were obtained from SMC at 17-22 weeks of gestation. Single cell suspensions of fetal liver tissues were made by previously reported methods [38]. Mononuclear cells (MNCs) were isolated from single cells of fetal liver tissues using Ficoll-Hypaque density gradient centrifugation and then washed with culture medium. Cells were seeded into $75 \mathrm{~cm}^{2}$ flasks at a density of $5 \times 10^{5}$ cells per $\mathrm{cm}^{2}$. After 3 to 5 days, non-adherent cells were removed by washing and then culture flasks were refilled with culture medium. At approximately $80 \%$ confluence, cells were detached with $0.25 \%$ trypsin and $1 \mathrm{mM}$ EDTA solution (HyClone Laboratories), plated into $75 \mathrm{~cm}^{2}$ culture flasks at a density of $5 \times 10^{5}$ cells per $\mathrm{cm}^{2}$, and cultured at $37^{\circ} \mathrm{C}$ under $5 \% \mathrm{CO}_{2}$ atmosphere. 


\section{Construction of human delta-like 1 (Dlk1) retroviral vector}

Human Dlk1 cDNA was synthesized from total RNA extracted from AFT024 cells expressing human Dlk1. cDNA synthesized was performed using $1 \mu \mathrm{g}$ of purified total RNA in a reaction volume of $20 \mu \mathrm{l}$ containing $250 \mathrm{mM}$ Tri- $\mathrm{HCl}, \mathrm{pH} 8.3,375 \mathrm{mM} \mathrm{KCl}$, $15 \mathrm{mM} \mathrm{MgCl} 2,0.1 \mathrm{M}$ DTT, $10 \mathrm{mM}$ each dNTP, 20 units of RNase inhibitor, $0.5 \mu \mathrm{g} / \mu \mathrm{l}$ oligo(dT)12-18 primer, and 200 units of SuperScript reverse transcriptase (Invitrogen). RT reaction was performed at $37^{\circ} \mathrm{C}$ for $1 \mathrm{hr}$. Synthesized cDNA samples were purified using a QIAquick PCR Purification Kit (Qiagen $\mathrm{GmbH}$ ) and used as a template for PCR. PCR primers for hDlk1 (accession number: MN003836) were specifically designed as follows: forward, 5'-GGGTCCATGACCGCGACCGAAGCC-3'; reverse, 5'CCTAGGTTAGATCTCCTCGTCGCC-3'. All amplicons were cloned into BamHI and AvrII sites of a pLXRN retroviral vector (Clontech Laboratories). The pLXRN vector and the purified hDlk1 DNA were linearized with BamHI and AvrII to prepare compatible ends for ligation using T4 DNA ligase (New England Biolabs).

\section{Transfection and production of retrovirus}

Retroviruses were prepared in GP2-293 cells, an HEK 293-based packing cell line. Transfection was performed in serum-free OptiMEM I (Invitrogen) with lipofectamine 2000 (Invitrogen). pLXRN-Dlk1 was transfected into GP2-293 cells with pVSV-G being, according to the manufacturer's instructions. At 8 to $10 \mathrm{~h}$ after transfection, culture medium was aspirated and then complete medium was added followed by incubation at $37^{\circ} \mathrm{C}$ for an additional 48 to $72 \mathrm{~h}$ under $5 \% \mathrm{CO}_{2}$ atmosphere. Supernatant containing viruses was filtered through a $0.22 \mu \mathrm{m}$ Steriflip filter (Millipore, MA, USA) through centrifugation at 50,000 g for $90 \mathrm{~min}$ at $4^{\circ} \mathrm{C}$. After removing the supernatant, viruses were resuspended in $1 \%$ of the original volume in TNE $(50 \mathrm{mM}$ Tris- $\mathrm{HCl}, \mathrm{pH} 7.8,130 \mathrm{mM}$ $\mathrm{NaCl}$, and $1 \mathrm{mM}$ EDTA) buffer and incubated at $4{ }^{\circ} \mathrm{C}$ overnight. 


\section{Infecting human fetal liver-derived mesenchymal stem cells (hFL-MSCs) with retroviruses}

Human fetal liver-derived MSCs were seeded into $75 \mathrm{~cm}^{2}$ flasks and cultured in culture medium ( $\alpha$-MEM supplemented 10\% FBS, $100 \mathrm{U} / \mathrm{ml}$ penicillin, and $100 \mu \mathrm{g} / \mathrm{ml}$ streptomycin) until 80\% confluence. MSCs were incubated with viruses at a multiplicity of infection (MOI) of 10 or 15 in MSCs culture medium containing $8 \mu \mathrm{g} / \mathrm{ml}$ polybrene. Infected cells were selected with $600 \mu \mathrm{g} / \mathrm{ml}$ neomycin G418 (Invitrogen) in culture medium at $37^{\circ} \mathrm{C}$ under $5 \% \mathrm{CO}_{2}$ for two weeks. At two weeks after selection, culture medium was freshly replaced.

\section{Immunofluorescence staining}

MSCs and Dlk1-expressing MSCs were plated onto chamber slides (Lab-Tek II; Nalge Nunc International), cultured at $37^{\circ} \mathrm{C}$ for 2 days, and immunofluorescence staining was performed by previously reported methods [8]. These stained slides were observed under an Olympus BX51 fluorescence microscope (Olympus). Photographs were taken with a microscope digital camera DP50 (Olympus) and analyzed using image-pro plus 5.1 software.

\section{Isolation of human $\mathrm{CD}^{+} 4^{+}$cells from umbilical cord blood}

Human CB samples were acquired from normal full-term deliveries after obtaining informed parental consent according to guidelines established by Samsung Medical Center, Seoul, Korea. Mononuclear cells (MNCs) were isolated using Ficoll-Hypaque density gradient centrifugation. $\mathrm{hCD} 34^{+}$cells were purified by previously reported methods [6-9]. The purity of isolated cells was estimated by flow cytometric analysis with antibodies specific for anti-hLin- fluorescein isothiocyanate (FITC) conjugate (Becton Dickinson, NJ, USA) and anti-hCD34-phycoerythrin (PE) conjugate (BD Pharmingen ${ }^{\mathrm{TM}}$, $\mathrm{CA}, \mathrm{USA})$. $\mathrm{hLin}^{-} \mathrm{hCD} 34^{+}$cells $(>95 \%)$ were used for the generation of humanized NSG mice. 
Humanized mice generated by intrahepatic co-injection with $\mathrm{hCD34}^{+} \mathrm{CB}$ cells and Dlk1-expressing MSCs or MSCs into conditioned neonatal NSG mice

Busulfan (busulfex, Ben Benue Laboratories) was dissolved in dimethyl sulfoxide (DMSO, Sigma Chemical), diluted in $0.9 \%$ saline, and then injected intravenously into newborn NSG mice via the facial vein at a dose of $15 \mathrm{mg} / \mathrm{kg}$ body weight in a total volume of $50 \mu \mathrm{l}$ [8]. At 8 to $24 \mathrm{~h}$ after injection, isolated hCD34 ${ }^{+}$cells and Dlk1-expressing MSCs or MSCs were co-injected into the liver of conditioned newborn NSG mice at a concentration of $2 \times 10^{5}$ cells of CB cells and $1 \times 10^{6}$ cells of Dlk1-expressing MSCs or MSCs.

\section{Flow cytometric analysis}

Peripheral blood mononuclear cells (PBMCs) were collected from tail veins of humanized NSG mice at 8, 12, 16, and 20 weeks after transplant. To remove red blood cells (RBCs), cells were treated with $1 \mathrm{X}$ RBC Lysis Buffer (eBioscience) according to the manufacturer's instructions. Single-cell suspensions were prepared, and mononuclear cells (MNCs) were isolated by previously reported methods [6-9]. Isolated MNCs were stained with hCD45- allophycocyanin (APC) conjugated, or -peridinin chlorophyll protein (PerCP)-Cy5.5 conjugate, hCD3-PerCP)-Cy5.5 conjugated, hCD8-, hHLA-DR-,

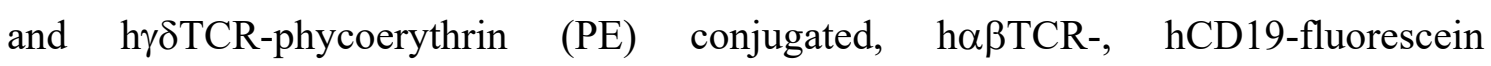
isothiocyanate (FITC) conjugated, or hCD45RO-PE-Cyanine 7 (Cy7) conjugated antibody. To characterize Dlk1-expressing MSCs and MSCs, hCD34-, hCD45-, hCD44-, hCD90-FITC, hCD73-, hCD105-, hHLA-DR-PE, and hCD14-APC conjugated antibodies were used. They were purchased from eBiosciences. Cells were stained with appropriate antibodies in $100 \mu \mathrm{PBS}$ containing $0.2 \% \mathrm{BSA}$ and $0.05 \%$ sodium azide for 15 min on ice. Flow cytometry analysis was performed using a FACSAria (BD Biosciences). Ten thousand to 1,000,000 events were acquired per sample and analyzed using FACSDiva (BD Biosciences) software and the data analyzes using FlowJo (BD Biosciences) software. 


\section{Immunohistochemistry}

Spleens were isolated from humanized mice and immunohistochemistry assay was performed by previously reported methods $[8,9]$. Stained slides were observed using an Olympus BX40 light microscope (Olympus) with 10X/22 numeric aperture and 40x/0.75 numeric aperture objective. Photographs were taken with a microscope digital camera DP50 (Olympus) and image-pro plus 5.1 software. All samples were counterstained with hematoxylin and eosin $(\mathrm{H} \& \mathrm{E})$.

\section{BrdU-labeling assay}

Spleen was isolated from humanized mice generated using hCD34 ${ }^{+} \mathrm{CB}$ cells together with hDlk1-expressing MSCs. To remove red blood cells (RBCs), cells were treated with 1X RBC Lysis Buffer (eBioscience) according to the manufacturer's instructions. Singlecell suspensions were prepared, and MNCs were isolated by previously reported methods [6-9]. For BrdU-labeling assay, we used Bromo-2'-deoxy-uridine Labeling and Detection Kit (Roche) according to the manufacturer's instructions. Briefly, $2 \times 10^{5} \mathrm{hCD}^{+}$cells were cultured with $1 \times 10^{5}$ MSCs or Dlk1-expressing MSCs irradiated at 30 Gy in the presence of hIL-2 (20 Unit $/ \mathrm{ml})$. At 3 days after culture, cells were stained with BrdU according to the manufacturer's instructions. Flow cytometry analysis was performed on a FACSAria (BD Biosciences). Ten thousand to 1,000,000 events were acquired per sample and analyzed using FACSDiva (BD Biosciences) or FlowJo (BD Biosciences) software.

\section{Mixed lymphocytes reaction (MLR) assay}

Human $\mathrm{CD}^{+}$lymphocytes as responder cells were isolated from spleens of humanized NSG mice using either a MACS human CD3 MicroBead Kit (Miltenyi Biotec) or an autoMACS ${ }^{\text {TM }}$ Cell Separator (Miltenyi Biotec) according to the manufacturer's instructions. MLR assay was performed by previously reported methods [8]. Briefly, 
stimulator cells were prepared from PBMCs of healthy human volunteers $(n=3)$ and irradiated at $30 \mathrm{~Gy}$. Then $2 \times 10^{5} \mathrm{hCD}^{+}$responder cells purified from the humanized mice were plated in triplicate into a 96-well U-bottom plate and incubated without or with irradiated $4 \times 10^{5}$ stimulator cells. After 3 days, MTT assay was performed to check cell proliferation according to the manufacture's instruction (Roche Diagnostics).

\section{Human cytokine release assay}

Human $\mathrm{CD}^{+}$lymphocytes were purified from humanized NSG mice as mentioned above. Human cytokine release assay was performed by previously reported methods [8]. Briefly, $1 \times 10^{6} \mathrm{hCD}^{+}$cells derived humanized NSG mice were plated in triplicate into 24 -well plates and co-cultured in the presence or absence of irradiated PBMCs $\left(2 \times 10^{6}\right.$ cells $)$ isolated from healthy human volunteers $(n=3)$. After 3 days, supernatants were harvested and levels of human cytokines such as hIL-2 and hIFN- $\gamma$ were measured using ELISA Ready-SET-go kit and according to the manufacture's instruction (eBioscience).

\section{Human TCR VB repertoire analysis}

Human TCR V $\beta$ repertories were analyzed with a TCR V $\beta$ repertoire kit (Beckman Coulter), as previously reported methods [8]. Samples were analyzed using a FACSAria (BD Biosciences). Data were analyzed using FACSDiva and GraphPad Prism software.

\section{Experimental EBV infection into humanized mice}

To produce EBV, B95-8 (Marmoset B-lymphoblastoid cell line) was used as described in the previous report [39]. Humanized mice were generated using hCD34 ${ }^{+} \mathrm{CB}$ cells alone $(n=10)$ or together with hDlk1-expressing FL-MSCs $(n=10)$ as described above. At 20 weeks after transplantation, humanized mice were challenged with $100 \mu \mathrm{l}$ EBV concentrate $\left(2 \times 10^{6} \mathrm{EBV}\right.$ copy or equivalent to approximately $1.5 \times 10^{3} \mathrm{TD}_{50}$ of $\mathrm{B} 95.8$ EBV virus solution.) was injected via intravenous injection. At 4 weeks after infection, 
peripheral blood samples were isolated from each group of humanized mice $(n=5$ in each group). Other mice ( $n=5$ in each group) were scarified and spleen cells were isolated.

\section{EBV-specific pentamer staining}

EBV-specific HLA-A*0201 pentamer (EBV LMP-1, YLLEMLWRL) was purchased from ProImmune Ltd (Oxford, UK). Peripheral blood and spleen were isolated from EBVchallenged humanized mice. To remove red blood cells (RBCs), cells were treated with 1X RBC Lysis Buffer (eBioscience) according to the manufacturer's instructions. Singlecell suspensions were prepared from peripheral blood and spleen using standard procedures: These cells were stained with anti-hCD45-APC, anti-hCD3-PerCP-Cy5.5, anti-hCD8-PE, and EBV-specific HLA-A*0201 pentamer was labeled with FITC in 100 $\mu \mathrm{PBS}$ containing $0.2 \% \mathrm{BSA}$ and $0.05 \%$ sodium azide for $30 \mathrm{~min}$ on ice. Flow cytometry analysis was performed on a FACSAria (BD Biosciences). Ten thousand to 1,000,000 events were acquired per sample and analyzed using a FACSDiva (BD Biosciences) or a FlowJo (BD Biosciences) software.

\section{Statistical analysis}

Data are presented as mean values \pm S.D. as indicated and analyzed using Student's twotailed $t$-test. The $p$-value was considered significant at values less than 0.05 , statistically significant $(* p<0.05, * * p<0.01, * * * p<0.001, * * * * p<0.0001)$. 


\section{Results}

\section{Experimental design and research issues}

In this study, we had two fundamental questions to be possibly addressed. Although previous reports have demonstrated immunomodulatory effects of mesenchymal stem cells (MSCs) on T cells [13-16, 24, 25], in vivo functions of MSCs related to T cells are experimentally insufficient. Therefore, we first asked whether MSCs could affect T cell development using humanized NSG mice co-injected with or without MSCs (Fig. 1a, Experiment I). If so, is it possible to regulate MSC-induced T cell development using delta-like 1 (Dlk1) molecule (Fig. 1b, Experiment II)? It is known that Notch-mediated signaling plays a key role in T cell development [32-34]. Additionally, Dlk1 putatively can interact with Notch1 receptor, thereby regulating cellular development [35-37]. To address the second issue, we generated humanized NSG mice (Fig. 1b, Experiment II). To address issues mentioned above, we performed an in vivo EBV-challenged experiment to see whether EBV-specific T cells could be mounted in the humanized mice (Fig. 1c, Experiment III).

\section{Human fetal liver-derived mesenchymal stem cells (hFL-MSCs) can suppress the development of human $T$ cells in NOD/SCID/IL-2R $\gamma^{\text {null }}$ (NSG) mice generated by intrahepatic co-injection with $\mathrm{hCD34}^{+}$cord blood $(\mathrm{CB})$ cells}

To explore the functional role of human MSCs (hMSCs) in the generation of human $\mathrm{T}$ cells in humanized mice, hMSCs were isolated from human fetal liver (hFL) as described in Materials and Methods. These cells were then incubated with antibodies specific for hCD14, hCD34, hCD45, hHLA-DR, hCD44, hCD73, hCD90, and hCD105 molecules. As shown in Fig. 2a and 2b, flow cytometric analysis revealed that these isolated MSCs were negative for hematopoietic or endothelial cell markers such as hCD14, hCD34, hCD45, and hHLA-DR (Fig. 2a), whereas they were significantly positive for MSC markers such as hCD44, hCD73, hCD90, and hCD105 (Fig. 2b) as compared with those of isotype control. The identity of MSC was consistent with that shown in previous reports 
$[40,41]$. By using isolated hMSCs and hCD $34^{+}$cord blood (CB) stem cells, humanized NOD/SCID/IL-2R $\gamma^{\text {null }}$ (NSG) mice were generated (Fig. 2C). Briefly, conditioned NSG newborn mice pre-treated with busulfan were intra-hepatically injected with hCD $34^{+} \mathrm{CB}$ stem cells alone or together with hMSC cells as depicted in Fig. 2c. To see the development of human T cells in humanized NSG mice, peripheral blood samples were isolated from tail vains at different times as indicated in Fig. $2 \mathrm{~d}$ and 2e. Cells were stained with antibodies specific for hCD45, hCD3, and hCD19 molecules. hCD45 $5^{+}$and $\mathrm{hCD} 5^{+} \mathrm{hCD}^{+} \mathrm{T}$ cells were gradually increased in humanized NSG mice injected with hCD $34^{+} \mathrm{CB}$ cells alone in a time dependent manner compared to those in humanized NSG mice injected with fetal liver-MSCs (FL-MSCs) plus hCD34 ${ }^{+} \mathrm{CB}$ cells (Figs. $2 \mathrm{~d}$ and $2 \mathrm{e}$, red circles vs. blue circles; Supplementary Fig. S1, hCD45 ${ }^{+}$cells; Supplementary Fig. S2, hCD $45^{+} \mathrm{hCD}^{+} \mathrm{T}$ cells), whereas marginal increases in $\mathrm{hCD} 45^{+} \mathrm{hCD} 19^{+}$cells could be seen in humanized NSG mice injected with FL-MSCs plus hCD34 ${ }^{+} \mathrm{CB}$ stem cells (Supplementary Fig. S3, red circles vs. blue circles), supposing that hMSCs might suppress the generation of human $\mathrm{T}$ cells in humanized NSG mice established by intrahepatic injection [8].

To verify the above results in more detail, humanized mice were scarified at 20 weeks after they were engrafted. Peripheral bloods and spleens were isolated as depicted in Fig. 3a. The reconstitution of human $\mathrm{T}$ and $\mathrm{B}$ cells was then evaluated using a flow cytometric analysis with antibodies to hCD45, hCD3, and hCD19 molecules. Similar to Figure $2 \mathrm{~d}, \mathrm{hCD} 45^{+}$cells were markedly increased in peripheral blood (Fig. 3b, $50 \pm 5 \%$ vs. $20 \pm 3 \%$; red bar vs. blue bar) and spleen (Fig. 3c, $80 \pm 5 \%$ vs. $41 \pm 5 \%$; red bar vs. blue bar) of humanized NSG mice generated with hCD34 ${ }^{+} \mathrm{CB}$ cells alone than those of humanized mice generated with hCD34 ${ }^{+} \mathrm{CB}$ cells together with FL-MSCs. Consistent with Fig. 2e, marked increases of hCD $45^{+}$hCD $3^{+}$cells could be observed in humanized NSG mice generated with hCD $34^{+} \mathrm{CB}$ cells alone than in humanized mice generated with hCD34 ${ }^{+} \mathrm{CB}$ cells together with FL-MSCs (Fig. 3d, peripheral blood, $65 \pm 4 \%$ vs. $3 \pm$ $0.5 \%$, red bar vs. blue bar; Fig. 3e, spleen, $62 \pm 9 \%$ vs. $0 \pm 0 \%$, red bar vs. blue bar). However, marginal differences in $\mathrm{hCD} 45^{+} \mathrm{hCD} 19^{+}$cells could be detected in both humanized NSG mice (hCD45 ${ }^{+} \mathrm{hCD} 19^{+}$cells in Fig. 3d, peripheral blood and Fig. 3e, spleen). Additionally, significant increase in $\mathrm{hCD}^{+}$cells in the spleen was confirmed 
using immunohistochemistry analysis (Fig. $3 \mathrm{f}, \mathrm{hCD} 34^{+} \mathrm{CB}$ cells alone vs. FL-MSCs + $\left.\mathrm{hCD} 34^{+} \mathrm{CB}\right)$. These results suggest that hFL-MSCs may induce the suppression of human T cell development in humanized NSG mice co-injected with hCD34 ${ }^{+} \mathrm{CB}$ cells.

\section{hDlk1-expressing MSCs cells promote the development of human $T$ cells in humanized NSG mice}

We have previously reported that notch signaling can facilitate the maintenance of selfrenewal of hCD34 $4^{+} \mathrm{CB}$ cells in vitro and that it can induce effective reconstitution of human T cells in vivo humanized mice [6]. The putative interaction between Dlk1 and notch 1 in vitro and in vivo can regulate normal tissue development [35-37]. It is known that Notch signaling plays a key role for initial commitment to the $\mathrm{T}$ cell lineage, thereby regulating subsequent steps of T cell development [32-34]. Therefore, we asked whether hDlk1-mediated Notch signaling could compensate the suppressive effect of hMSCs in T cell development. To explore this issue, hDlk1-expressing hFL-MSCs (FL-MSCs-Dlk1) cells were generated. The hDlk1 gene was then cloned and inserted into retroviral vector (Supplementary Fig. S4) as described in Materials and Methods. hDlk1-contained retroviruses were stably transduced into isolated FL-MSCs as described in Material and Methods. hDlk1 expression was then confirmed by immunofluorescence microscopy (Fig. 4a, FL-MSCs $v s$. FL-MSCs-Dlk1). Next, to rule out the possibility that the expression of hDlk1 could affect characteristics of MSCs, FL-MSCs-Dlk1 cells were characterized using antibodies as described in Figs. $2 \mathrm{a}$ and 2b. Consistently, hDlk1-expressed MSCs showed strong expression of MSC markers such as hCD44, hCD73, hCD90, and hCD105 (Fig. 4b), but not hematopoietic or endothelial cell markers such as hCD14, hCD34, hCD45, or hHLA-DR (Fig. 4c).

We then further generated humanized NSG mice injected with hCD34 ${ }^{+} \mathrm{CB}$ cells alone or hCD34 ${ }^{+} \mathrm{CB}$ cells plus FL-MSCs-Dlk1 cells as depicted in Fig. 4d. At 20 weeks after engrafting cells, cells were isolated from peripheral bloods and spleens of humanized NSG mice and subjected to flow cytometric analysis to assess the development of human $\mathrm{T}$ and $\mathrm{B}$ cells. Interestingly, $\mathrm{hCD} 45^{+} \mathrm{hCD}^{+}$cells were significantly increased in the peripheral blood of humanized NSG mice generated with FL-MSCs-Dlk1 plus hCD34 ${ }^{+}$ 
$\mathrm{CB}$ cells than in the peripheral blood of humanized mice generated with hCD $34^{+} \mathrm{CB}$ cells alone (Fig. 4e, $95 \pm 1 \%$ vs. $62 \pm 9 \%$; absolute number of $\mathrm{hCD}^{+} 5^{+} \mathrm{hCD} 3^{+}$cells, closed green bar vs. closed red bar). A similar increase of hCD $45^{+} \mathrm{hCD} 3^{+}$cells could be detected in spleens of humanized NSG mice generated with FL-MSCs-Dlk1 plus hCD $34^{+} \mathrm{CB}$ cells (Fig. 4f, $94 \pm 3 \%$ vs. $65 \pm 4 \%$; absolute number of hCD $45^{+}$hCD $3^{+}$cells, closed green bar vs. closed red bar). Such significant increase was also confirmed by immunohistochemistry analysis of spleen (Fig. 4g, hCD3 in FL-MSCs-Dlk1 + hCD34 ${ }^{+}$ $\mathrm{CB} v s . \mathrm{hCD}^{2} 4^{+} \mathrm{CB}$ cells alone). However, marked attenuation of $\mathrm{hCD} 45^{+} \mathrm{hCD} 19^{+}$cells were observed in humanized mice generated with FL-MSCs-Dlk1 plus hCD34 ${ }^{+} \mathrm{CB}$ cells than in humanized mice generated with $\mathrm{hCD}^{+} 4^{+} \mathrm{CB}$ cells alone (Fig. 4e and Fig. 4f, hCD $45^{+} \mathrm{hCD} 19^{+}$cells; absolute number of $\mathrm{hCD} 45^{+} \mathrm{hCD} 19^{+}$cells, closed green bar $v s$. closed red bar). These results suggest that hDlk1-expressing FL-MSCs eells may facilitate the development of human $\mathrm{T}$ cells, whereas they might suppress the development of human B cells in humanized NSG mice generated with FL-MSCs-Dlk1 plus hCD34 ${ }^{+} \mathrm{CB}$ cells.

\section{Human $\mathrm{T}$ cells developed in humanized NSG mice co-injected with $\mathrm{hCD34}^{+} \mathrm{CB}$ cells plus FL-MSCs-Dlk1 cells show driver $T$ cell repertoires and immune-competitive cells restricted to human MHC}

Since the development of human T cells markedly appeared in humanized NSG mice generated with FL-MSCs-Dlk1 plus hCD34 ${ }^{+} \mathrm{CB}$ cells, we assessed whether these T cells could be drivers in terms of TCR repertoire and whether they could functionally recognize human MHC molecules. In order to do that, PBMCs were isolated from humanized NSG mice at 20 weeks after engraftment. Their diversities were then compared with those of normal human PBMCs. When cells were stained with antibodies to twenty-four V $\beta$-T cell usages, human T cells derived from humanized NSG mice were significantly diverse, similar to the diversity of normal human periphery (Fig. 5a: yellow square, normal human PBMCs; red square, PBMCs of hCD34 ${ }^{+} \mathrm{CB}$ cells only; green square, PBMCs of hDlk1expressed MSCs plus hCD34 ${ }^{+} \mathrm{CB}$ cells), indicating T cells developed in humanized NSG mice had a diverse repertoire of $\mathrm{V} \beta$-T cells receptors. Next, we asked whether human $\mathrm{T}$ 
cells could functionally recognize human MHC molecules. In order to do that, we performed mixed lymphocyte reaction (MLR) assay. Human $\mathrm{CD}^{+} \mathrm{T}$ cells as responder cells were purified from spleens of both humanized NSG mice. Stimulator cells were prepared from allogenic PBMCs of human healthy volunteers. Human $\mathrm{CD}^{+} \mathrm{T}$ cells derived from humanized NSG mice were co-cultured with different responder cells for 3 days. PMBCs derived from both humanized NSG mice showed significant proliferation in the presence of allogenic human PBMCs (Fig. 5b, hPBMCs-1, hPBMCs-2, and hPBMCs-3). Interestingly, the proliferative ability was much higher for $\mathrm{T}$ cells derived from humanized NSG mice generated with hDlk1-expressed MSCs plus hCD34 ${ }^{+} \mathrm{CB}$ cells than in T cells derived from humanized NSG mice generated with hCD34 ${ }^{+} \mathrm{CB}$ cells alone (Fig. 5b, closed green bars vs. closed red bars). When human cytokines such as hIFN- $\gamma$ and hIL- 2 were measured in cultures after MLR reaction, levels of hIFN- $\gamma$ and hIL-2 were significantly higher in T cells derived from humanized NSG mice generated with hDlk1expressed MSCs plus hCD34 ${ }^{+} \mathrm{CB}$ cells (Fig. 5c, hIFN- $\gamma$; Fig. 5d, hIL-2). These results suggest that human T cells derived from humanized NSG mice generated by hDlk1expressed MSCs plus hCD34 ${ }^{+} \mathrm{CB}$ cells are restricted to human MHC molecules.

\section{EBV-specific T cells are effectively generated in humanized NSG mice obtained using hDlk1-expressing MSCs plus hCD34 ${ }^{+} \mathrm{CB}$ cells}

Having shown the above results, we finally examined whether antigen-specific human $\mathrm{T}$ cell response could be effectively mounted in humanized NSG mice. In order to do that, $1.5 \times 10^{3} \mathrm{TD}_{50}$ of a B95-8 strain of EBV was inoculated into humanized NSG mice (Fig 6a) as described in Materials and Methods. At four weeks after inoculation, mice were sacrificed and human $\mathrm{T}$ cell responses in peripheral blood and spleen to challenged EBV were characterized. $\mathrm{hCD} 45^{+} \mathrm{hCD} 3^{+}$cells were significantly higher in humanized NSG mice generated by hDlk1-expressing MSCs plus hCD34 ${ }^{+} \mathrm{CB}$ cells than that those in humanized NSG mice generated using hCD34+ $\mathrm{CB}$ cells alone (Fig. 6b, peripheral blood: $23 \pm 3 \%$ vs. $13 \pm 4 \%$; Fig. 6c, spleen: $26 \pm 3 \%$ vs. $17 \pm 4 \%$ ). To assess antigen-specific $\mathrm{T}$ cells against EBV, we evaluated EBV-specific hCD8 ${ }^{+} \mathrm{T}$ cells in humanized NSG mice. EBV pentamer staining results revealed that $\mathrm{hCD} 45^{+} \mathrm{hCD} 3^{+} \mathrm{hCD} 8^{+} \mathrm{EBV}$ pentamer ${ }^{+}$cells 
were significantly higher in peripheral blood and spleen of humanized NSG mice generated using hDlk1-expressed MSCs plus hCD34 ${ }^{+} \mathrm{CB}$ cells than those of humanized NSG mice generated using hCD34 ${ }^{+} \mathrm{CB}$ cells alone (Fig. $6 \mathrm{~d}$, peripheral blood: $23.7 \pm 4.2 \%$ vs. $9.2 \pm 3.5 \%$; Fig. 6e, spleen: $1.4 \pm 0.8 \%$ vs. $0.2 \pm 0.1 \%$ ). Consistently, absolute EBVspecific $\mathrm{hCD}^{+} \mathrm{T}$ cell numbers were elevated in the peripheral blood and spleen of humanized NSG mice generated by hDlk1-expressed MSCs plus hCD34 ${ }^{+} \mathrm{CB}$ cells (Fig. 6d, peripheral blood, closed red bar vs. closed green bar; Fig. 6e, spleen, closed red bar vs. closed green bar). These results suggest that EBV-specific $\mathrm{hCD}^{+} \mathrm{T}$ cells are efficiently mounted in humanized mice generated by hDlk1-expressing MSCs plus hCD $34^{+} \mathrm{CB}$ cells than those in humanized mice generated by using hCD $34^{+} \mathrm{CB}$ cells.

Having shown the above results, we further tried to identify activated $\mathrm{T}$ cells, phenotypically presented as $\mathrm{hCD} 45^{+} \mathrm{hCD} 3^{+} \mathrm{hCD} 8^{+} \mathrm{hCD} 45 \mathrm{RO}^{+} \mathrm{hHLA}-\mathrm{DR}{ }^{+} \mathrm{T}$ cells [42], in the peripheral blood and spleens of humanized mice challenged with EBV. Percentage and absolute number of activated $\mathrm{T}$ cells in the peripheral blood were significantly increased in humanized mice generated using hDlk1-expressing MSCs plus hCD34 ${ }^{+} \mathrm{CB}$ cells than in humanized mice generated using hCD34 ${ }^{+} \mathrm{CB}$ cells alone (Fig. $7 \mathrm{a}, 48 \pm 6 \%$ vs. $37 \pm 3 \%$; Fig. $7 \mathrm{~b}$, closed green bar vs. closed red bar). Although the percentage of activated $\mathrm{T}$ cells in spleens were lower in humanized mice generated using hDlk1expressing MSCs plus hCD34 ${ }^{+} \mathrm{CB}$ cells than in humanized mice generated using hCD34 ${ }^{+}$ CB cells (Fig. 7c, $36 \pm 7 \%$ vs. $68 \pm 5 \%$ ), the absolute number of cells was significantly higher in humanized mice generated using hDlk1-expressing MSCs plus hCD34 ${ }^{+} \mathrm{CB}$ cells (Fig. 7d, closed green bar vs. closed red bar). Altogether, these results suggest that EBV-specific $\mathrm{CD}^{+}$and activated $\mathrm{T}$ cells are effectively generated in humanized mice generated using hDlk1-expressing MSCs plus hCD34 ${ }^{+} \mathrm{CB}$ cells than in humanized mice generated using hCD34 $4^{+} \mathrm{CB}$ cells alone. 


\section{Discussion}

In the present study, we examined in vivo roles of MSCs and Dlk1 in the development and generation of human T cells using humanized NSG mice model established by intrahepatic injection of $\mathrm{hCD} 34^{+} \mathrm{CB}$ cells [8]. We found that human $\mathrm{T}$ cell development was severely attenuated in humanized mice co-injected with FL-MSCs, whereas it was markedly recovered in humanized mice co-injected with hDlk1-expressing FL-MSCs. After challenge with EBV, interestingly, EBV-specific $\mathrm{CD}^{+} \mathrm{T}$ cells were effectively mounted in humanized mice co-injected with hDlk1-expressing FL-MSCs. More importantly, activated $\mathrm{T}$ cells were significantly elevated in humanized mice than in humanized mice generated with $\mathrm{hCD} 34^{+} \mathrm{CB}$ cells alone. These results suggest that Dlk1 can promote human $\mathrm{T}$ cell development, thereby functionally enhancing antigen-specific $\mathrm{T}$ cell responses in humanized mice.

Functional roles of MSC in immune response, especially in T cell response, are mostly associated with immunosuppressive effects [13-16, 23-25]. The inhibitory function of MSCs is achieved by either inhibiting proliferation of $\mathrm{T}$ cells or regulating antigen-presentation of DCs [43]. Regarding the in vivo function of MSCs, however, direct evidence remains unclear. To address the in vivo function of MSCs, in this study, we utilized humanized NSG mice generated by intrahepatic injection of hCD34 ${ }^{+} \mathrm{CB}$ cells [8]. Co-injection of FL-MSCs into humanized mice resulted in marked attenuation of human T cells. Interestingly, FL-MSCs were markedly detected in the liver and spleen (Supplementary Fig. S5). Moreover, human T cells developed in the humanized mice were detected as $\alpha \beta \mathrm{T}$ cells (Supplementary Fig. S6). Considering previous reports showing that fetal liver injected with $\mathrm{hCD} 34^{+} \mathrm{CB}$ cells can effectively provide an environment for $\mathrm{T}$ cell development [8], MSCs in the liver and spleen might be functionally involved in T cell development and proliferation in humanized NSG mice, thereby leading to suppressive effects on T cell development and generation. Our results are consistent with immunomodulatory effects of MSCs reported previously [23-25].

With these results, we further addressed whether Dlk1 could affect $\mathrm{T}$ cell development and generation in humanized mice. It has been well demonstrated that Notch signaling critically regulates cell fate decisions and T cell lineage commitment [32-34]. 
Moreover, it has been reported that Dlk1 putatively can interact with Notch1, thereby regulating cellular development [35-37]. Therefore, we generated hDlk1-expressing MSCs and humanized NSG mice injected with hCD34 ${ }^{+} \mathrm{CB}$ cells plus hDlk1-expressing MSCs. Interestingly, we found marked increases of human $\mathrm{T}$ cells in humanized mice. Moreover, these human T cells were functionally active and proliferated in the presence of hIL-2 (Supplementary Fig. S7). Having shown these results, we further asked whether antigen-specific $\mathrm{T}$ cell response could be effectively mounted in humanized mice generated with hCD34 ${ }^{+} \mathrm{CB}$ cells plus hDlk1-expressing MSCs. After challenge of EBV, EBV-specific $\mathrm{CD} 8^{+} \mathrm{T}$ cells and $\mathrm{hCD} 45^{+} \mathrm{hCD}^{+}{ }^{+} \mathrm{hCD}{ }^{+}{ }^{+} \mathrm{hCD} 45 \mathrm{RO}^{+} \mathrm{hHLA}-\mathrm{DR}{ }^{+}$activated $\mathrm{T}$ cells were significantly enhanced in humanized mice. Although the molecular and cellular mechanism by which how Dlk1 is functionally associated with the T cell development and generation could not be addressed in this study, based on previous reports and our current findings, Dlk1 might be able to facilitate $\mathrm{T}$ cell development and induce $\mathrm{T}$ cell proliferation presumably through Notch signaling, thereby effectively inducing antigenspecific $\mathrm{T}$ cell responses in humanized mice.

Based on results from three different experimental sets of humanized NSG mice, we have two conclusions. First, the in vivo function of MSCs in T cell development of humanized NSG mice experimentally established by intrahepatic injection might be functionally associated with immunosuppressive effects. Second, Dlk1 molecule can enhance T cell development and generation in humanized NSG mice, thereby facilitating antigen-specific T cell response. Although the cellular and molecular mechanism setting off the immunosuppressive in vivo effect of MSCs in T cell development and generation of the humanized NSG mice remains unclear, considering therapeutic impacts of MSCs in translational researches, including infectious and regenerative immune diseases, and functional importance of Dlk1-Notch signaling in cell fate decision, our data and humanized NSG mice might contribute to the development of therapeutics targeting various human diseases as a potential animal model system. 


\section{Acknowledgments}

The authors thank the members of the Hyehwa forum for helpful discussions. 


\section{References}

1. Shultz LD, Ishikawa F, Greiner DL. Humanized mice in translational biomedical research. Nat Rev Immunol. 2007;7(2):118-30.

2. Manz MG. Human-hemato-lymphoid-system mice: opportunities and challenges. Immunity. 2007;26(5):537-41.

3. Macchiarini F, Manz MG, Palucka AK, Shultz LD. Humanized mice: are we there yet? J Exp Med. 2005;202(10):1307-11.

4. Payne KJ, Crooks GM. Immune-cell lineage commitment: translation from mice to humans. Immunity. 2007;26(6):674-7.

5. Melkus MW, Estes JD, Padgett-Thomas A, Gatlin J, Denton PW, Othieno FA, et al. Humanized mice mount specific adaptive and innate immune responses to EBV and TSST-1. Nat Med. 2006;12(11):1316-22.

6. Choi B, Chun E, Kim SY, Kim M, Lee KY, Kim SJ. Notch-induced hIL-6 production facilitates the maintenance of self-renewal of hCD34+ cord blood cells through the activation of Jak-PI3K-STAT3 pathway. Am J Pathol. 2012;180(1):351-64.

7. Kim M, Choi B, Kim SY, Yang JH, Rho CR, Lee KY, et al. Co-transplantation of fetal bone tissue facilitates the development and reconstitution in human B cells in humanized NOD/SCID/IL-2R $\gamma^{\text {null }}$ (NSG) mice. J Clin Immunol. 2011;31(4):699-709.

8. Choi B, Chun E, Kim M, Kim SY, Kim ST, Yoon K, et al. Human T cell development in the liver of humanized NOD/SCID/IL-2R $\gamma($ null)(NSG) mice generated by intrahepatic injection of CD34(+) human (h) cord blood (CB) cells. Clin Immunol. 2011;139(3):321-35.

9. Choi B, Chun E, Kim M, Kim ST, Yoon K, Lee KY, et al. Human B cell development and antibody production in humanized NOD/SCID/IL-2R $\gamma($ null) (NSG) mice conditioned by busulfan. J Clin Immunol. 2011;31(2):253-64.

10. Choi B, Lee JS, Kim SJ, Hong D, Park JB, Lee KY. Anti-tumor effects of anti-PD-1 antibody, pembrolizumab, in humanized NSG PDX mice xenografted with 
dedifferentiated liposarcoma. Cancer Lett. 2020;478:56-69.

11. Mosier DE, Gulizia RJ, Baird SM, Wilson DB. Transfer of a functional human immune system to mice with severe combined immunodeficiency. Nature. 1988;335(6187):256-9.

12. Yu CI, Gallegos M, Marches F, Zurawski G, Ramilo O, García-Sastre A, et al. Broad influenza-specific CD8+ T-cell responses in humanized mice vaccinated with influenza virus vaccines. Blood. 2008;112(9):3671-8.

13. Weiss ARR, Dahlke MH. Immunomodulation by Mesenchymal Stem Cells (MSCs): Mechanisms of Action of Living, Apoptotic, and Dead MSCs. Front Immunol. 2019;10:1191.

14. Kadle RL, Abdou SA, Villarreal-Ponce AP, Soares MA, Sultan DL, David JA, et al. Microenvironmental cues enhance mesenchymal stem cell-mediated immunomodulation and regulatory T-cell expansion. PLoS One. 2018;13(3):e0193178.

15. Wang LT, Jiang SS, Ting CH, Hsu PJ, Chang CC, Sytwu HK, et al. Differentiation of Mesenchymal Stem Cells from Human Induced Pluripotent Stem Cells Results in Downregulation of c-Myc and DNA Replication Pathways with Immunomodulation Toward CD4 and CD8 Cells. Stem Cells. 2018;36(6):903-14.

16. Song N, Scholtemeijer M, Shah K. Mesenchymal Stem Cell Immunomodulation: Mechanisms and Therapeutic Potential. Trends Pharmacol Sci. 2020;41(9):653-64.

17. Nolta JA, Hanley MB, Kohn DB. Sustained human hematopoiesis in immunodeficient mice by cotransplantation of marrow stroma expressing human interleukin-3: analysis of gene transduction of long-lived progenitors. Blood. 1994;83(10):3041-51.

18. Nolta JA, Thiemann FT, Arakawa-Hoyt J, Dao MA, Barsky LW, Lemischka IR, et al. The AFT024 stromal cell line supports long-term ex vivo maintenance of engrafting multipotent human hematopoietic progenitors. Leukemia. 2002;16(3):352-61.

19. Brouard N, Chapel A, Neildez-Nguyen TM, Granotier C, Khazaal I, Péault B, et al. Transplantation of stromal cells transduced with the human IL3 gene to stimulate 
hematopoiesis in human fetal bone grafts in non-obese, diabetic-severe combined immunodeficiency mice. Leukemia. 1998;12(7):1128-35.

20. Noort WA, Kruisselbrink AB, in't Anker PS, Kruger M, van Bezooijen RL, de Paus RA, et al. Mesenchymal stem cells promote engraftment of human umbilical cord blood-derived CD34(+) cells in NOD/SCID mice. Exp Hematol. 2002;30(8):870-8.

21. Koç ON, Lazarus HM. Mesenchymal stem cells: heading into the clinic. Bone Marrow Transplant. 2001;27(3):235-9.

22. Koç ON, Gerson SL, Cooper BW, Dyhouse SM, Haynesworth SE, Caplan AI, et al. Rapid hematopoietic recovery after coinfusion of autologous-blood stem cells and culture-expanded marrow mesenchymal stem cells in advanced breast cancer patients receiving high-dose chemotherapy. J Clin Oncol. 2000;18(2):307-16.

23. Haddad R, Saldanha-Araujo F. Mechanisms of T-cell immunosuppression by mesenchymal stromal cells: what do we know so far? Biomed Res Int. 2014;2014:216806.

24. Selmani Z, Naji A, Zidi I, Favier B, Gaiffe E, Obert L, et al. Human leukocyte antigen-G5 secretion by human mesenchymal stem cells is required to suppress $\mathrm{T}$ lymphocyte and natural killer function and to induce CD4+CD25highFOXP3+ regulatory T cells. Stem Cells. 2008;26(1):212-22.

25. Nasef A, Zhang YZ, Mazurier C, Bouchet S, Bensidhoum M, Francois S, et al. Selected Stro-1-enriched bone marrow stromal cells display a major suppressive effect on lymphocyte proliferation. Int J Lab Hematol. 2009;31(1):9-19.

26. Djouad F, Plence P, Bony C, Tropel P, Apparailly F, Sany J, et al. Immunosuppressive effect of mesenchymal stem cells favors tumor growth in allogeneic animals. Blood. 2003;102(10):3837-44.

27. Abdel aziz MT, El Asmar MF, Atta HM, Mahfouz S, Fouad HH, Roshdy NK, et al. Efficacy of mesenchymal stem cells in suppression of hepatocarcinorigenesis in rats: possible role of Wnt signaling. J Exp Clin Cancer Res. 2011;30(1):49.

28. Kumar BV, Connors TJ, Farber DL. Human T Cell Development, Localization, and 
Function throughout Life. Immunity. 2018;48(2):202-13.

29. Coutinho A, Caramalho I, Seixas E, Demengeot J. Thymic commitment of regulatory T cells is a pathway of TCR-dependent selection that isolates repertoires undergoing positive or negative selection. Curr Top Microbiol Immunol. 2005;293:43-71.

30. Coutinho A, Salaün J, Corbel C, Bandeira A, Le Douarin N. The role of thymic epithelium in the establishment of transplantation tolerance. Immunol Rev. 1993;133:225-40.

31. Modigliani Y, Bandeira A, Coutinho A. A model for developmentally acquired thymus-dependent tolerance to central and peripheral antigens. Immunol Rev. 1996;149:155-20.

32. Li X, von Boehmer H. Notch Signaling in T-Cell Development and T-ALL. ISRN Hematol. 2011;2011:921706.

33. Garbe AI, Krueger A, Gounari F, Zúñiga-Pflücker JC, von Boehmer H. Differential synergy of Notch and $\mathrm{T}$ cell receptor signaling determines alphabeta versus gammadelta lineage fate. J Exp Med. 2006;203(6):1579-90.

34. Van de Walle I, Waegemans E, De Medts J, De Smet G, De Smedt M, Snauwaert S, et al. Specific Notch receptor-ligand interactions control human TCR- $\alpha \beta / \gamma \delta$ development by inducing differential Notch signal strength. J Exp Med. 2013;210(4):683-97.

35. Traustadóttir GÁ, Jensen CH, Thomassen M, Beck HC, Mortensen SB, Laborda J, et al. Evidence of non-canonical NOTCH signaling: Delta-like 1 homolog (DLK1) directly interacts with the NOTCH1 receptor in mammals. Cell Signal. 2016;28(4):246-54.

36. Sánchez-Solana B, Nueda ML, Ruvira MD, Ruiz-Hidalgo MJ, Monsalve EM, Rivero $\mathrm{S}$, et al. The EGF-like proteins DLK1 and DLK2 function as inhibitory non-canonical ligands of NOTCH1 receptor that modulate each other's activities. Biochim Biophys Acta. 2011;1813(6):1153-64.

37. Traustadóttir GÁ, Jensen CH, Garcia Ramirez JJ, Beck HC, Sheikh SP, Andersen DC. 
The non-canonical NOTCH1 ligand Delta-like 1 homolog (DLK1) self interacts in mammals. Int J Biol Macromol. 2017;97:460-7.

38. in 't Anker PS, Noort WA, Scherjon SA, et al. Mesenchymal stem cells in human second-trimester bone marrow, liver, lung, and spleen exhibit a similar immunophenotype but a heterogeneous multilineage differentiation potential. Haematologica. 2003;88(8):845-852.

39. Lee EK, Joo EH, Song KA, Choi B, Kim M, Kim SH, Kim SJ, Kang MS. Effects of lymphocyte profile on development of EBV-induced lymphoma subtypes in humanized mice. Proc Natl Acad Sci USA. 2015;112(42):13081-6.

40. Delorme B, Charbord P. Culture and characterization of human bone marrow mesenchymal stem cells. Methods Mol Med. 2007;140:67-81.

41. Tran TC, Kimura K, Nagano M, Yamashita T, Ohenda K, Sugimori H, et al. Identification of human placenta-derived mesenchymal stem cells involved in reendothelialization. J Cell Physiol. 2011;226(1):224-35.

42. Coleman CB, Lang J, Sweet LA, Smith NA, Freed BM, Pan Z, et al. Epstein-Barr Virus Type 2 Infects T Cells and Induces B Cell Lymphomagenesis in Humanized Mice. J Virol. 2018;92(21):e00813-8.

43. Joel MDM, Yuan J, Wang J, Yan Y, Qian H, Zhang X, et al. MSC: immunoregulatory effects, roles on neutrophils and evolving clinical potentials. Am J Transl Res. 2019;11(6):3890-904. 


\section{Figure legends}

Fig. 1. Experimental designs for the generation of humanized NSG mice in this study. Three sets of humanized NSG mice were designed and generated, represented as Experiment I (a, green lines), Experiment II (b, blue lines), and Experiment III (c, red lines) as described in Materials and Methods. (a) Experiment I: hCD34 ${ }^{+} \mathrm{CB}$ cells or hCD34 ${ }^{+} \mathrm{CB}$ cells plus hMSCs $\left(\mathrm{hDlk}^{-}\right)$cells were injected into livers of newborn NSG mice. (b) Experiment II: hCD $34^{+} \mathrm{CB}$ cells or hCD34 ${ }^{+} \mathrm{CB}$ cells plus $\mathrm{hDlk}{ }^{+} \mathrm{hMSC}$ cells were injected into livers of newborn NSG mice. Reconstitution of human T and B cells was assessed in humanized NSG mice as described in the main text. (c) Experiment III: Humanized NSG mice were generated with hCD $34^{+} \mathrm{CB}$ cells or hCD34 ${ }^{+} \mathrm{CB}$ cells plus $\mathrm{hDlk}^{+} \mathrm{hMSCs}$ cells. After 20 weeks, EBV was used to challenge humanized NSG mice as described in Materials and Methods.

Fig. 2. Generation of humanized NSG mice engrafted with $\mathrm{hCD}^{+} 4^{+} \mathrm{CB}$ cells together with MSCs.

(a and b) Human MSCs were prepared from fetal liver tissues as described in Materials and methods. These cells were stained with anti-CD14, anti-CD34, anti-CD45, anti-HLADR, anti-CD44, anti-CD73, anti-CD90, and anti-CD105 antibodies followed by flow cytometry analysis. Isotype antibody in each sample was used as control. (c) Schematic diagram showing the generation of humanized NSG mice. Busulfan was intravenously injected into NSG newborn mice $(n=30)$. After $24 \mathrm{~h}, \mathrm{hCD} 34^{+} \mathrm{CB}$ cells alone $(n=15)$ or together with hFL-MSC cells $(n=15)$ were co-injected into livers of conditioned newborn NSG mice as described in Materials and method. (d and e) Peripheral blood samples were isolated from humanized NSG mice generated by using hCD34 ${ }^{+} \mathrm{CB}$ cells alone $(n=5)$ or together with MSCs $(n=5)$ at different time points as indicated. These cells were then stained with anti-hCD45 and anti-hCD3 antibody followed by flow cytometry analysis on a FACSAria. Ten thousand to 1,000,000 events were acquired per sample and $\mathrm{hCD} 45^{+}(\mathbf{d})$ and $\mathrm{hCD} 45^{+} \mathrm{hCD}^{+}$(e) were analyzed using FACSDiva software. Percentages of cells were obtained by manual flow cytometric gating method. Data are shown as the average of five different mice in each group ( $\pm \mathrm{S} . \mathrm{D}) .{ }^{*}, p<0.05 ; * * *, p<$ $0.001 ; * * *, p<0.0001$. 
Fig. 3. Human $T$ cell development is suppressed in humanized NSG mice generated with $\mathrm{hCD34}^{+} \mathrm{CB}$ cells together with $\mathrm{h}-\mathrm{FL}-\mathrm{MSCs}$.

(a) Schematic diagram showing the generation of humanized NSG mice. Busulfan was intravenously injected into NSG newborn mice $(n=30)$. After $24 \mathrm{~h}, \mathrm{hCD} 34^{+} \mathrm{CB}$ cells alone $(n=15)$ or together with hFL-MSC cells $(n=15)$ were co-injected into livers of conditioned newborn NSG mice as described in Materials and Methods. (b-e) Peripheral blood (b and $\mathbf{d}$ ) and spleen (c and e) tissues samples were isolated from humanized NSG mice generated with hCD $34^{+} \mathrm{CB}$ cells alone $(n=8)$ or together with hFL-MSCs $(n=8)$. These cells were stained with anti-hCD45, anti-hCD3, and anti-hCD19 antibodies as described in Materials and methods. Percentages and absolute numbers of cells were obtained by manual flow cytometric gating and counted. Data are presented as the average of eight different mice in each group ( \pm S.D). ${ }^{* * * *}, p<0.0001$. (f) Spleens were isolated from humanized NSG mice, fixed with $10 \%$ formalin, and embedded in paraffin. Paraffin embedded tissue sections were stained with hematoxylin and eosin (H\&E) and anti-hCD3 antibody as described in Materials and Methods. Stained slides were observed using an Olympus BX40 light microscope. Photographs were taken with a microscope digital camera DP50 and analyzed with an Image-pro plus 5.1 software.

Fig. 4. Generation of humanized NSG mice engrafted with $\mathrm{hCD}^{+} \mathrm{CB}$ cells together with human delta-like 1 (hDlk1)-expressing MSCs.

(a) Human FL- MSCs were incubated with viruses at a multiplicity of infection (MOI) of 10 or 15 in FL-MSCs culture medium containing $8 \mu \mathrm{g} / \mathrm{ml}$ polybrene. These transduced cells were selected for two weeks as described in Materials and Methods. Immunofluorescence staining was performed for hFL-MSC or hDlk1-expressing hFLMSC cells as described in Materials and Methods. Stained slides were observed using an Olympus BX51 fluorescence microscope. Photographs were taken with a microscope digital camera DP50 and analyzed using an Image-pro plus 5.1 software. (b and c) hDlk1expressing hFL-MSC cells were stained with anti-CD14, anti-CD34, anti-CD45, antiHLA-DR, anti-CD44, anti-CD73, anti-CD90, and anti-CD105 antibodies followed by flow cytometry analysis. Isotype antibody in each sample was used as control. (d) 
Schematic diagram showing the generation of humanized NSG mice. Busulfan was intravenously injected into NSG newborn mice $(n=30)$. After $24 \mathrm{~h}$, hCD34 ${ }^{+} \mathrm{CB}$ cells alone $(n=15)$ or together with hFL-MSC-hDlk1 cells $(n=15)$ were co-injected into livers of conditioned newborn NSG mice as described in Materials and method. (e and $\mathbf{f}$ ) Peripheral blood (e) and spleen (f) tissues samples were isolated from humanized NSG mice generated with hCD34 ${ }^{+} \mathrm{CB}$ cells alone $(n=8)$ or together with hFL-MSCs-hDlk $(n$ $=8$ ). Cells were stained with anti-hCD45, anti-hCD3, and anti-hCD19 antibodies as described in Materials and methods. Percentages and absolute numbers of cells were obtained by manual flow cytometric gating and counted. Data are presented as average values of eight different mice in each group ( \pm S.D $)$. **, $p<0.01 ; * * *, p<0.001$; ****, $p<0.0001$. (g) Spleens were isolated from humanized NSG mice, fixed in 10\% formalin, and embedded in paraffin. Paraffin embedded tissue sections were stained for hematoxylin and eosin (H\&E) and anti-hCD3 antibody as described in Materials and Methods. Stained slides were observed using an Olympus BX40 light microscope. Photographs were taken with a microscope digital camera DP50 and analyzed with an Image-pro plus 5.1 software.

Fig. 5. Characterization of humanized mice generated with hDlk1-expressing FLMSCs and $\mathrm{hCD}^{+} \mathrm{CB}$ cells.

(a) Peripheral blood samples were isolated from humanized mice generated with hCD34 ${ }^{+}$ CB cells alone $(n=5)$ or together with hDlk1-expresing MSC cells $(n=5)$ as described in Fig. 4D. Single cells were prepared as described in Materials and Methods. These cells were stained with a TCR V $\beta$ repertoire kit according to the manufacturer's instructions. PBMCs were also isolated from normal healthy volunteers $(n=3)$ and stained with the TCR V $\beta$ repertoire kit. Samples were analyzed using a FACSAria. Data are presented as the average of triplicate samples $\left( \pm\right.$ S.D). (b) Human $\mathrm{CD}^{+}$lymphocytes as responder cells were isolated from spleens of humanized NSG mice and then used for MLR assay as described in Materials and methods. Data are presented as the average of triplicate samples ( \pm S.D). ${ }^{*}, \mathrm{p}<0.05 . * *, p<0.01{ }^{* * *}, p<0.001$. (c and d) Purified human $\mathrm{CD}^{+}$ $\mathrm{T}$ cells were co-cultured in the presence or absence of irradiated PBMCs isolated from healthy human volunteers as described in Materials and methods. After 3 days, 
supernatants were harvested and levels of human cytokines such as hIFN- $\gamma(\mathbf{c})$ and hIL-2 (d) were measured with ELISA Kits according to the manufacture's instruction. Data are presented as the average of triplicate samples ( \pm S.D). ${ }^{*}, p<0.05 ; * *, p<0.01$.

\section{Fig. 6. EBV infection induces the generation of $\mathrm{EBV}$-specific $\mathrm{T}$ cells in humanized} NSG mice generated with hDlk1-expressing hFL-MSCs.

(a) A protocol for performing EBV infection. Humanized NSG mice were generated with hCD34 ${ }^{+} \mathrm{CB}$ cells alone $(n=10)$ or together with hDlk1-expressing hFL-MSCs $(n=10)$ as described in Materials and methods. After 20 weeks, EBVs were injected to humanized mice via intravenous infection as described in Materials and Methods. (b and c) At 4 weeks after EBV infection, peripheral blood (b) and spleen tissue (c) samples were isolated from humanized mice generated with hCD $34^{+} \mathrm{CB}$ cells alone $(n=5)$ or together with hDlk1-expressing hFL-MSCs $(n=5)$. Cells were prepared as described in Materials and Methods and stained with anti-hCD45 and hCD3 antibodies. Percentages of cells were obtained by manual flow cytometric gating method. Data are presented as the average of triplicate samples ( \pm S.D). (d and e) PBMCs $(\mathbf{d}, n=5)$ and spleen $(\mathbf{e}, n=5)$ were isolated from humanized NSG mice. Cells stained with anti-hCD45, anti-hCD3, anti-hCD8, and anti-EBV pentamer as described in Materials and methods. Percentages and absolute numbers of cells were obtained by manual flow cytometric gating and counted. Data are presented as the average of triplicate samples $( \pm \mathrm{S} . \mathrm{D}) .{ }^{* * *}, p<0.001$; $* * * *, p<0.0001$.

Fig. 7. Activated T cells are elevated in humanized NSG mice generated with hDlk1expressing hFL-MSCs.

(a and b) At 4 weeks after EBV infection, peripheral bloods were isolated from humanized mice generated with hCD $34^{+} \mathrm{CB}$ cells alone $(n=5)$ or together with hDlk1expressing hFL-MSCs $(n=5)$. Cells were prepared as described in Materials and methods and stained with anti-hCD45, hCD3, hCD8, hCD45RO, and hHLA-DR antibodies. Percentages (a) and absolute numbers (b) of cells were obtained by manual flow cytometric gating and counted. Data are presented as the average of triplicate samples $( \pm$ S.D). ${ }^{* * * *}, p<0.0001$. (c and d) At 4 weeks after EBV infection, spleen tissues were 
isolated from humanized mice generated with hCD $34^{+} \mathrm{CB}$ cells alone $(n=5)$ or together with hDlk1-expressing hFL-MSCs $(n=5)$. Cells are prepared, as described in Materials and methods and stained with anti-hCD45, hCD3, hCD8, hCD45RO, and hHLA-DR antibodies. Percentages (c) and absolute numbers (d) of cells were obtained by manual flow cytometric gating and counted. Data are presented as the average of triplicate samples ( \pm S.D $) . * * * *, p<0.0001$. 


\section{Newborn NSG mouse}

a Experiment I

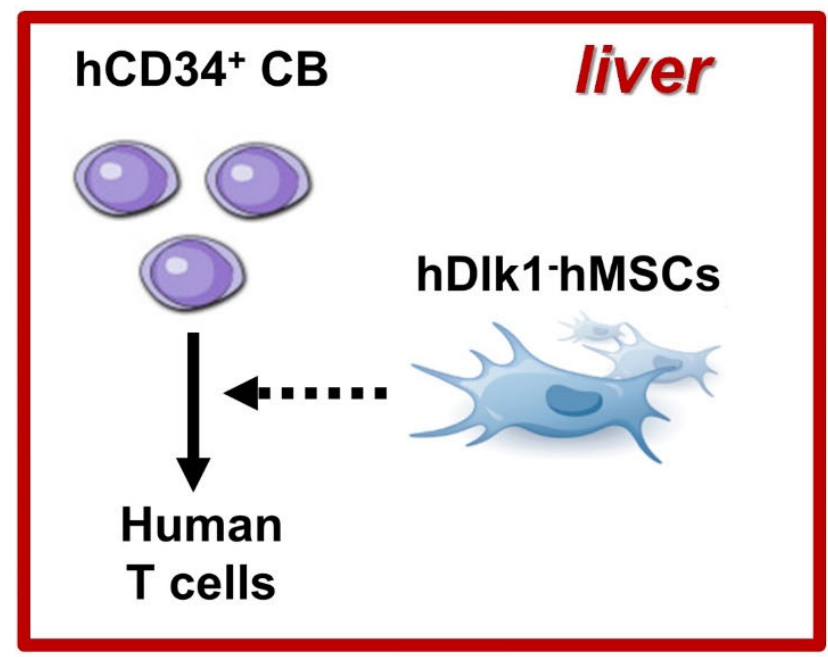

20 weeks

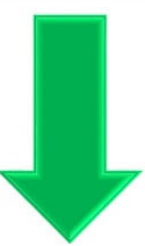

Humanized NSG mouse

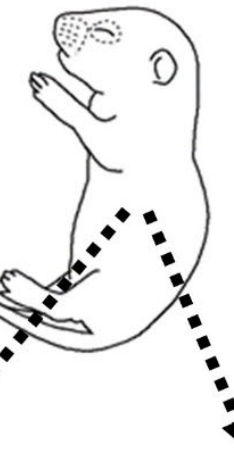

- b Experiment II

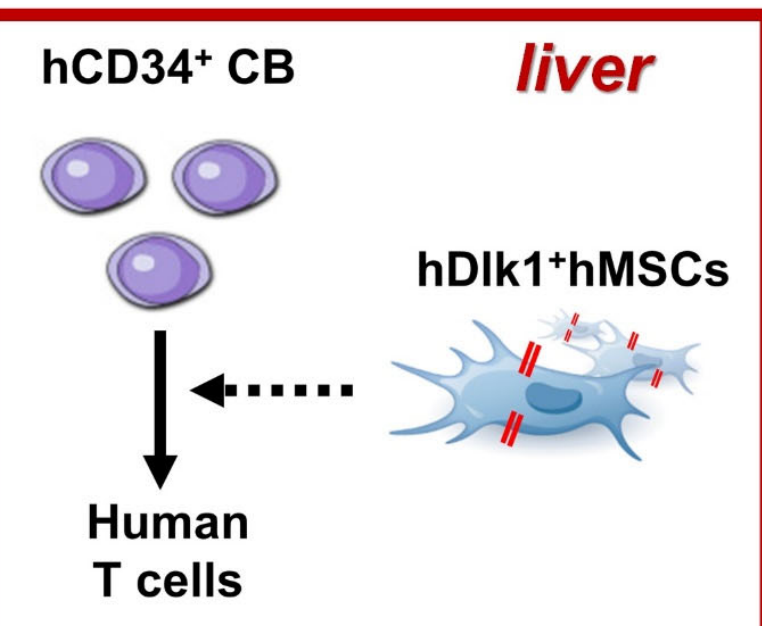

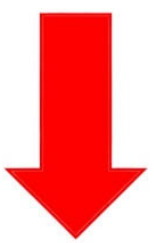

c Experiment III

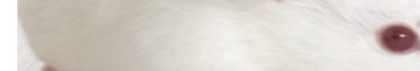

$a$ $E B V$ infection

Phenotype analysis
EBV-specific $T$ cells 
a

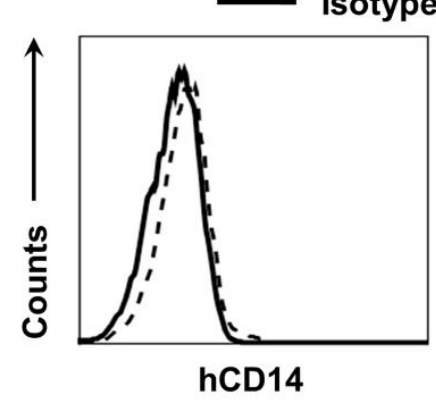

b
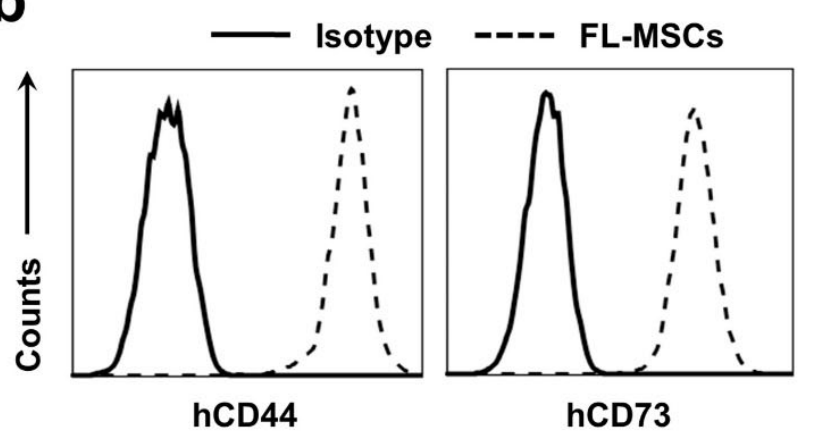

d
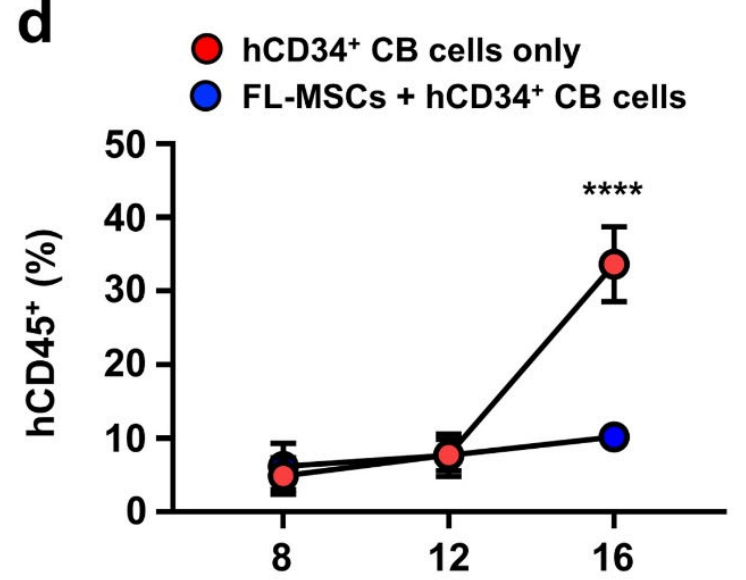

Weeks after injection

FL-MSCs

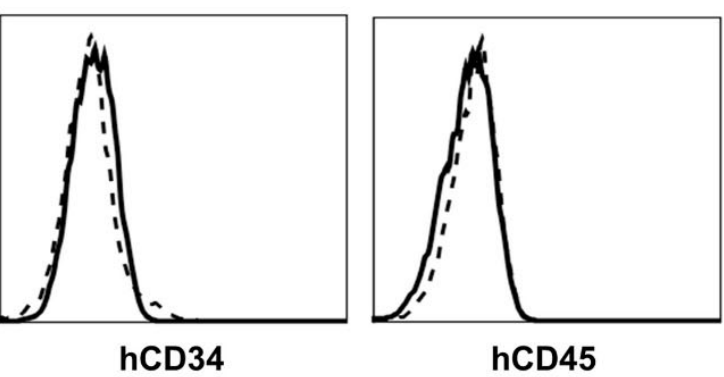

hCD45

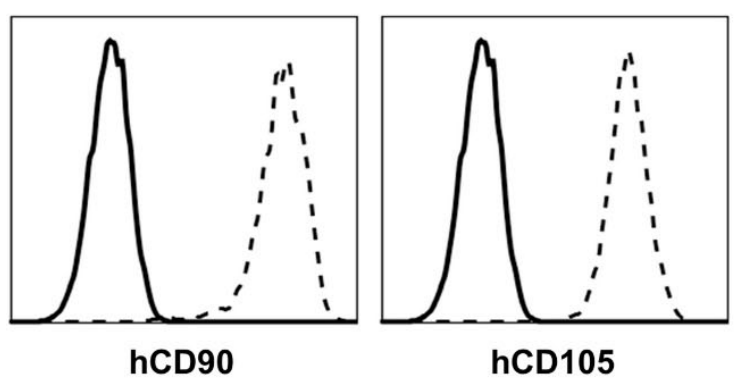

e

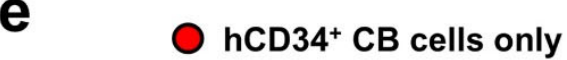

O FL-MSCs + hCD34 ${ }^{+}$CB cells

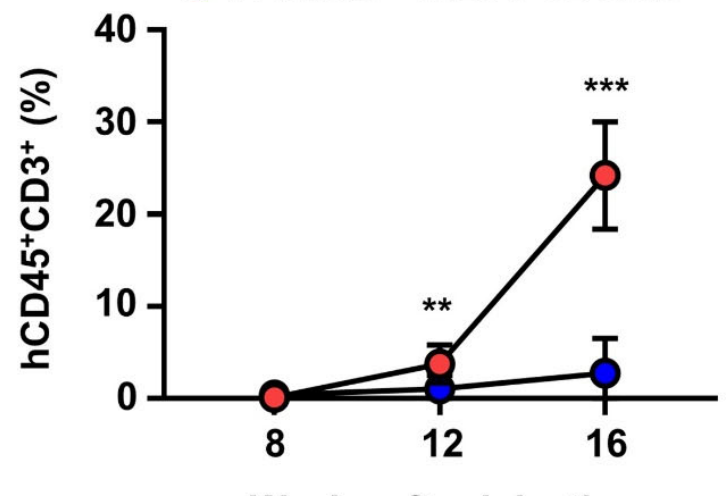

Weeks after injection
C
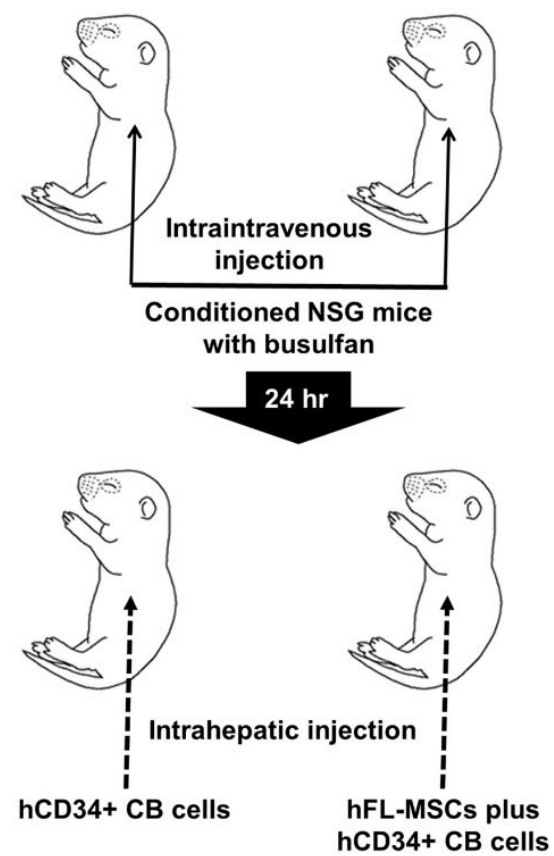

12,16

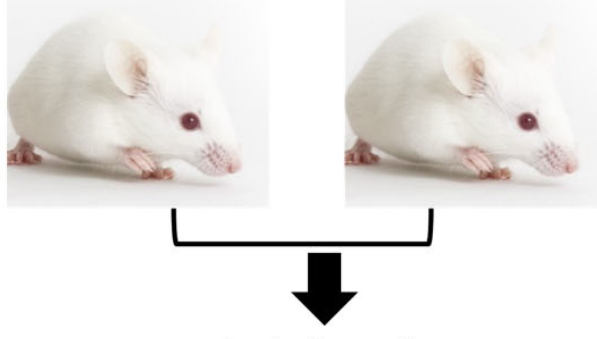

Isolation of

Peripheral blood,

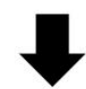

Flow cytometric analysis

Kwon et al., Figure 2 

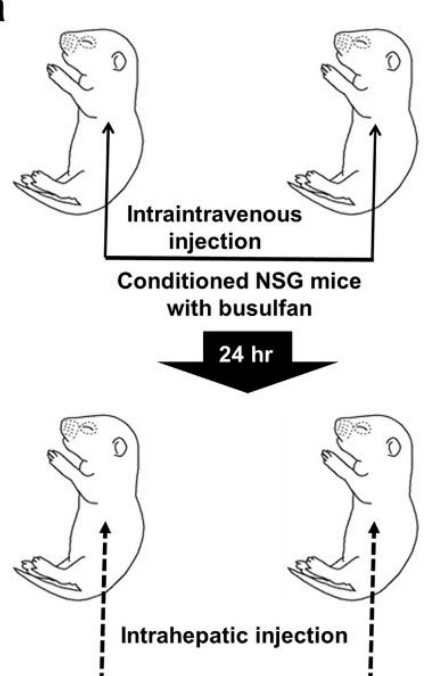

hCD34+ CB cells FL-MSCs plus hCD34+ CB cells
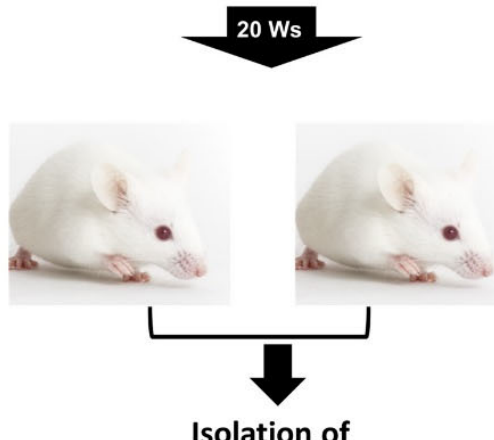

Peripheral blood and spleen

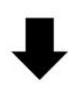

Flow cytometric analysis \&

Immunohistochemistry analysis b

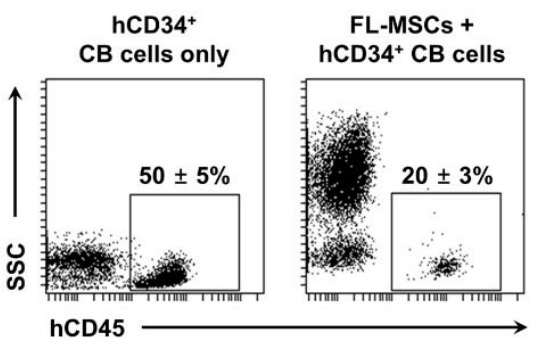

C $\begin{gathered}\mathrm{hCD}^{+} 4^{+} \\ \mathrm{CB} \text { cells only }\end{gathered}$

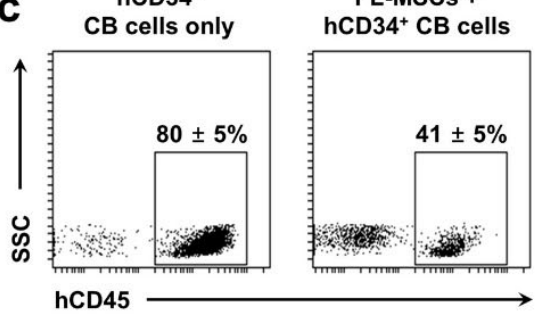

hCD45 d
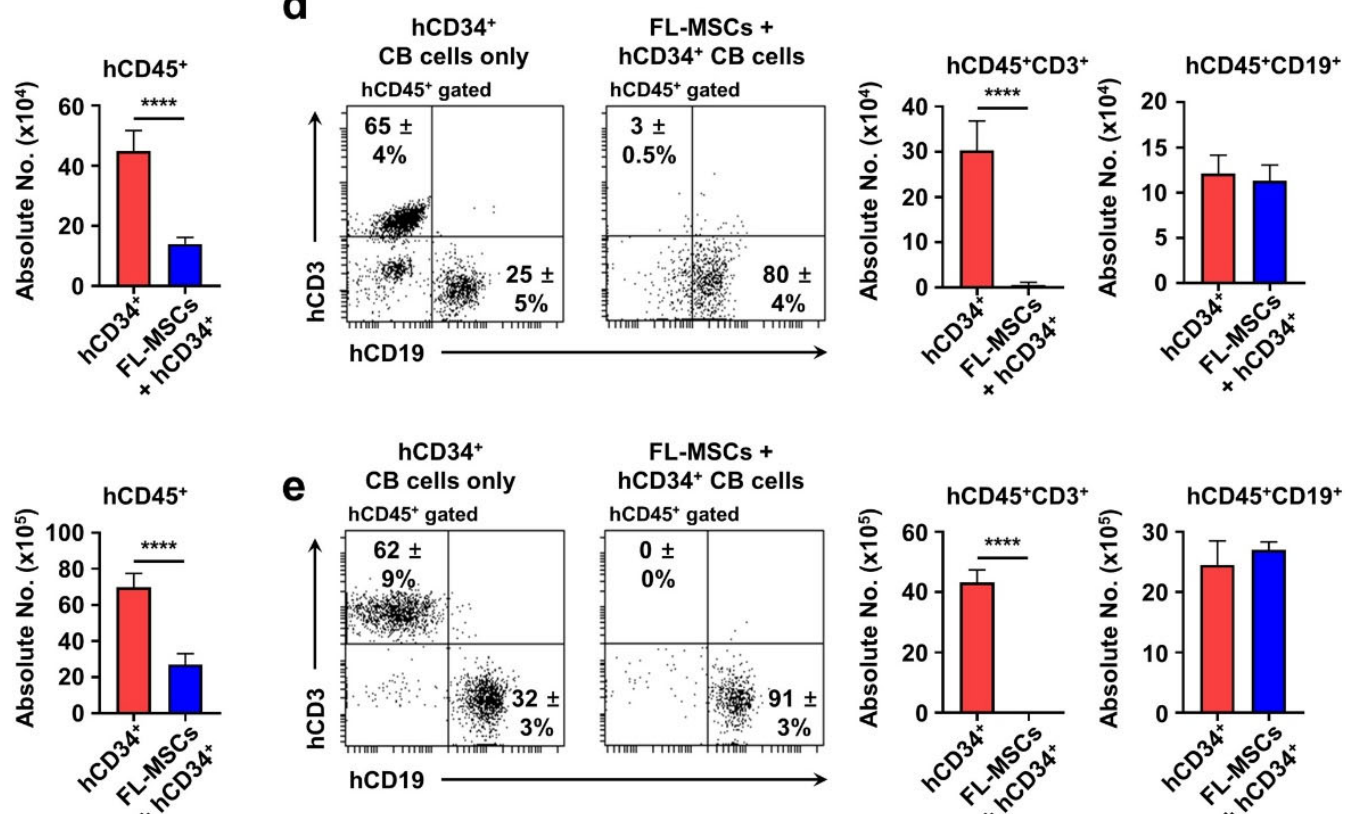

e CB cells only

FL-MSCs +
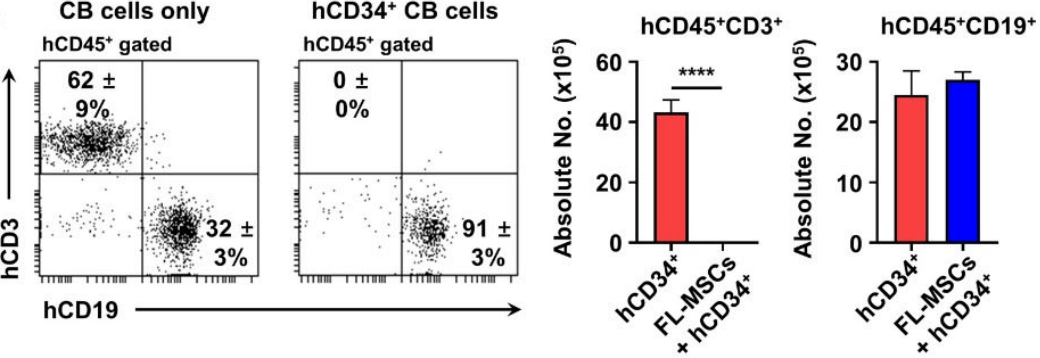

f
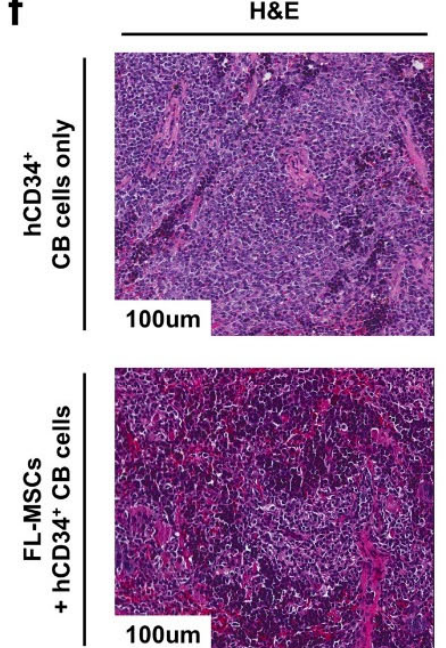

hCD3
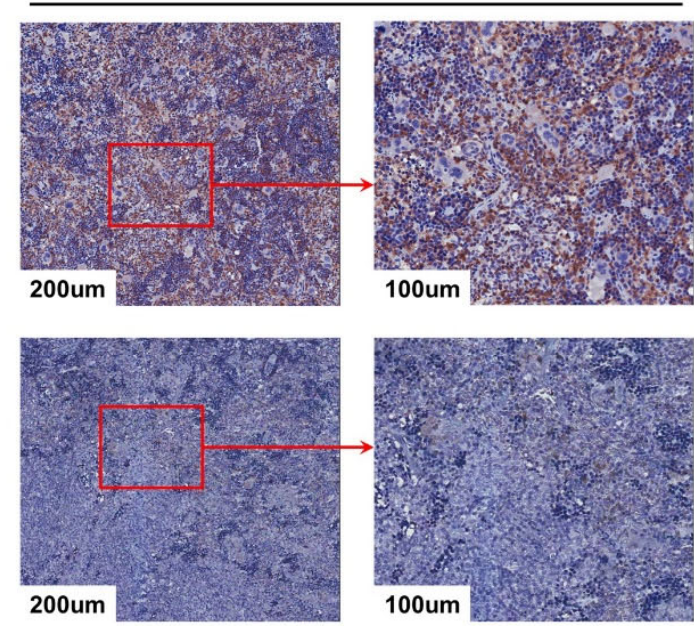
a

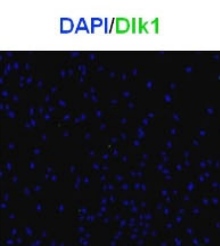

FL-MSC-DIk1

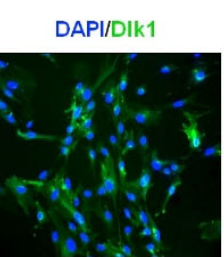

b

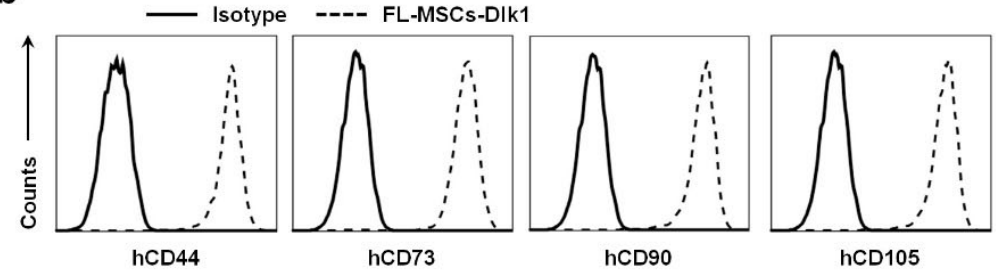

C

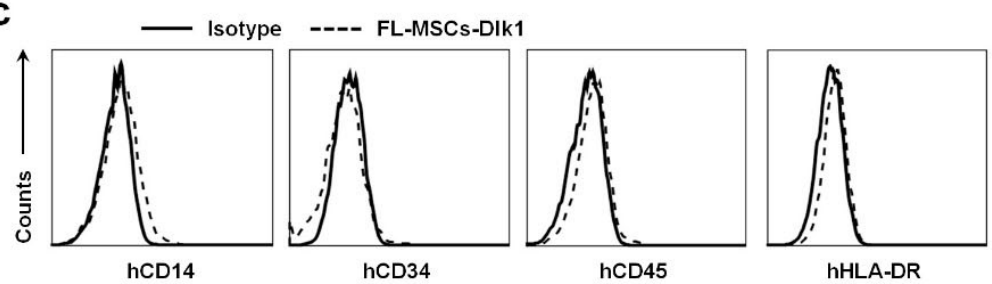

d
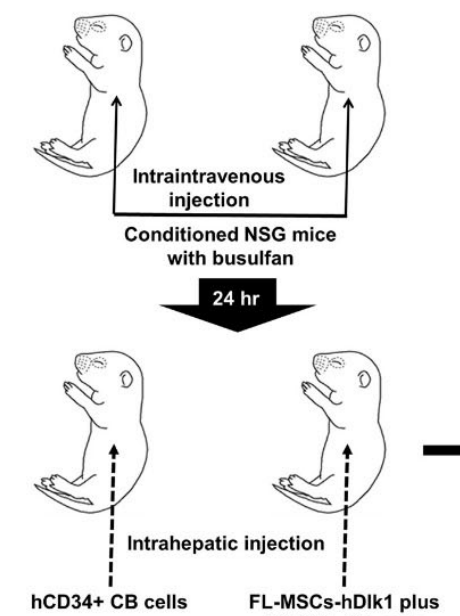

hCD34+ CB cells
FL-MSCs-hDlk1 plus
hCD34+CB cells

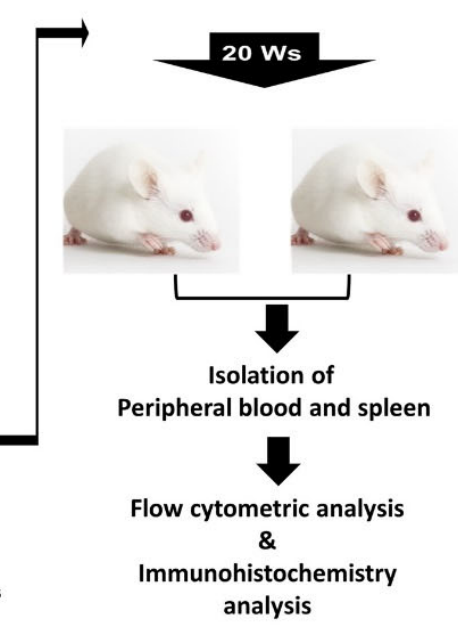

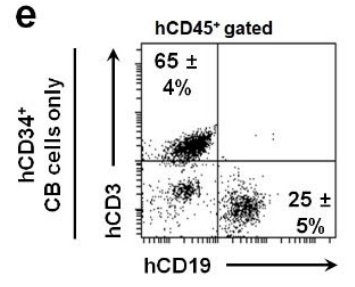
hCD45+ gated
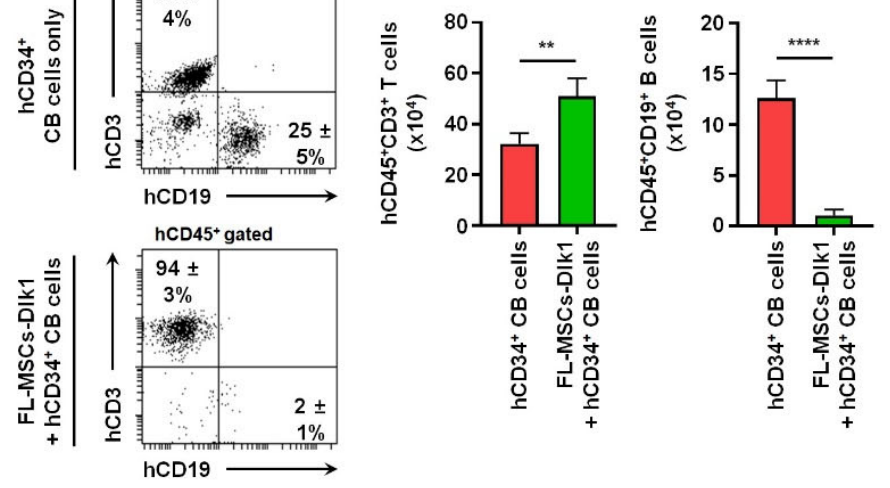

f
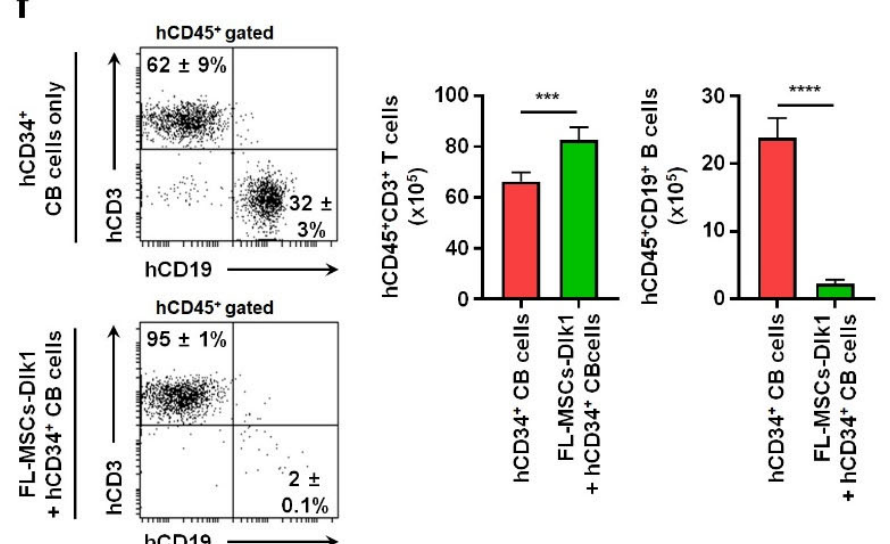

g
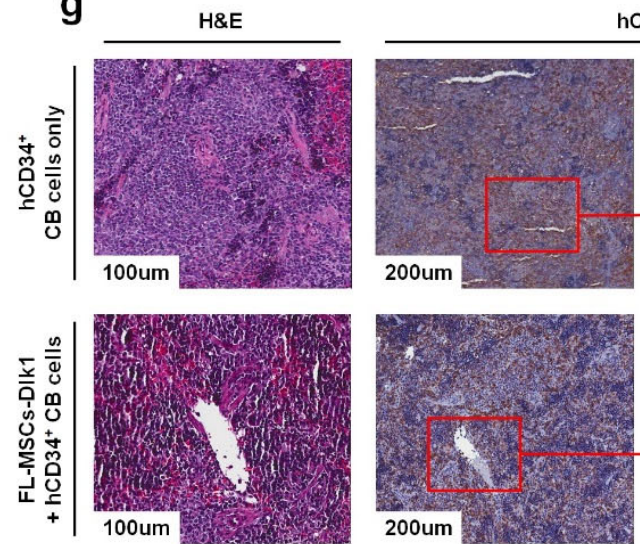

hCD3

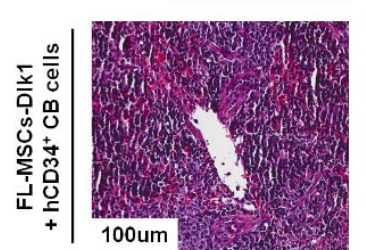

Kwon et al., Figure 4 


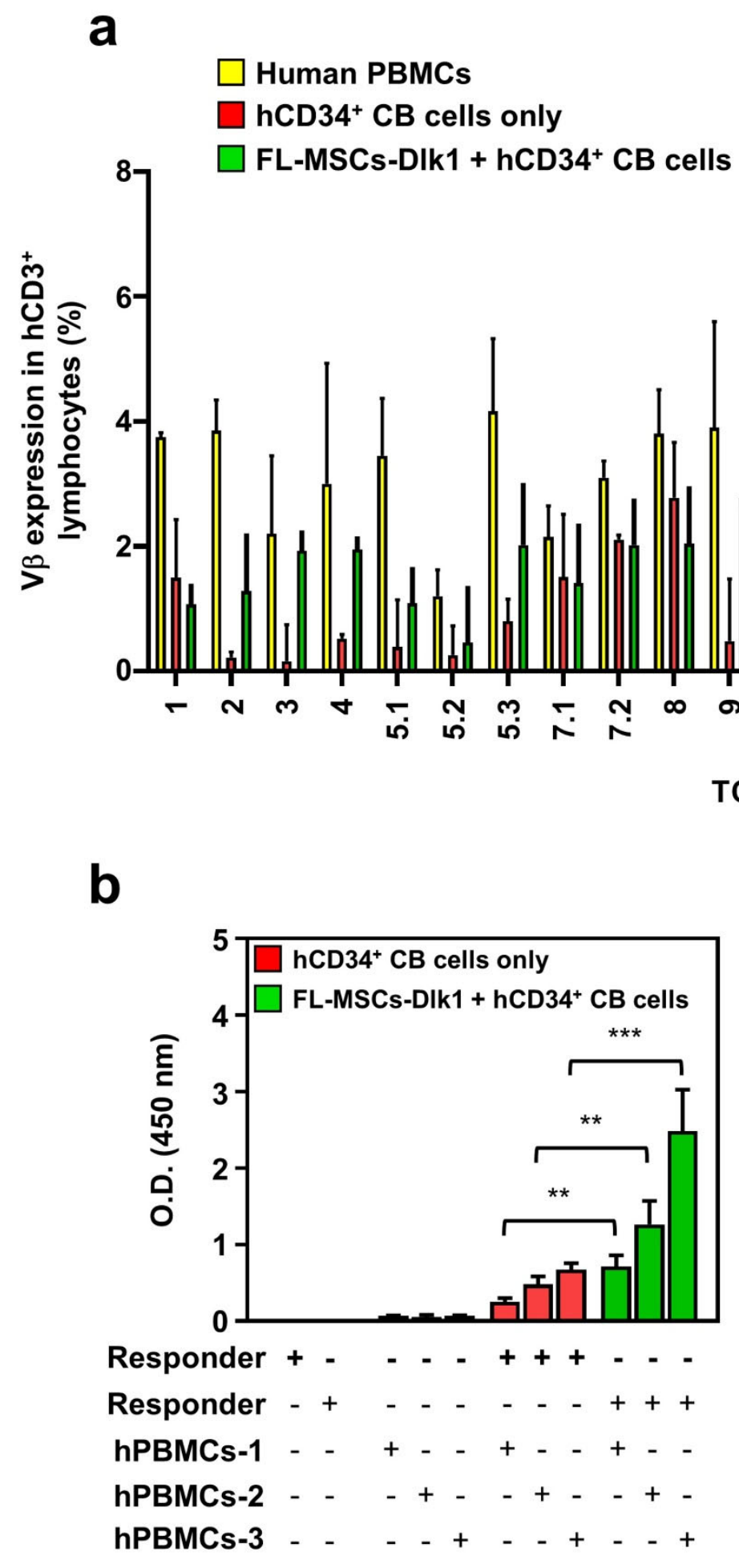

C

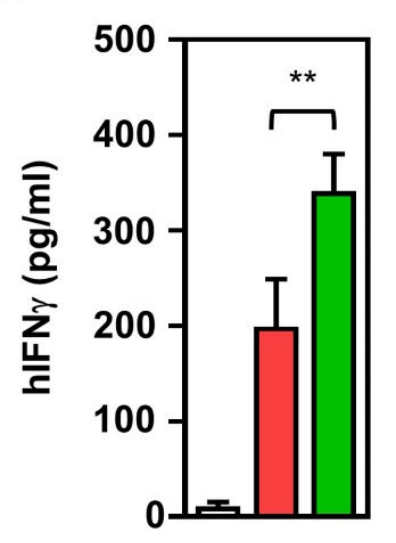

d

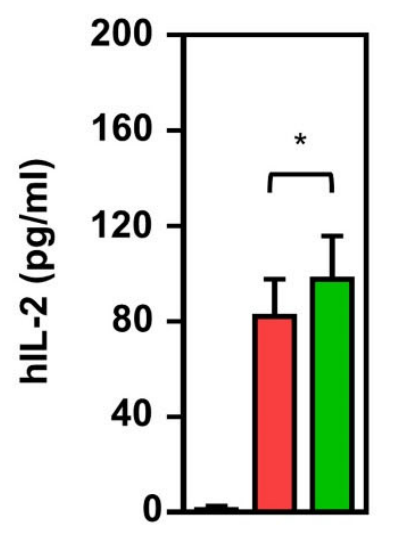

Responder only

hCD34+ $C B$ cells only

FL-MSCs-Dlk1 + hCD34+ CB cells 
a
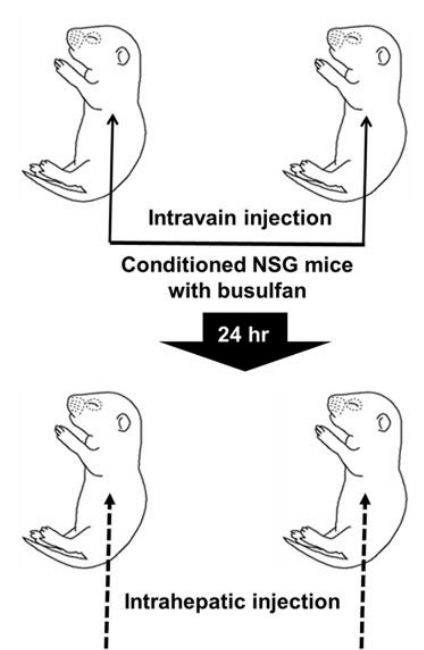

hCD34+ CB cells hFL-MSCs-hDIk1 plus hCD34+ CB cells
hes
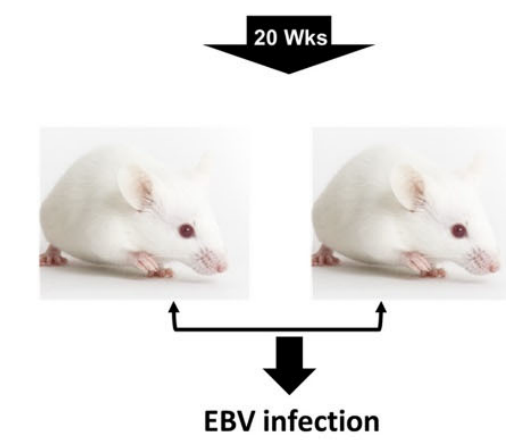
(intravain injection)

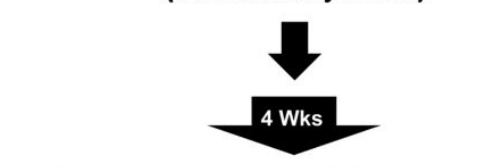

Killed, isolated peripheral blood and spleen, and flow cytometric analysis b
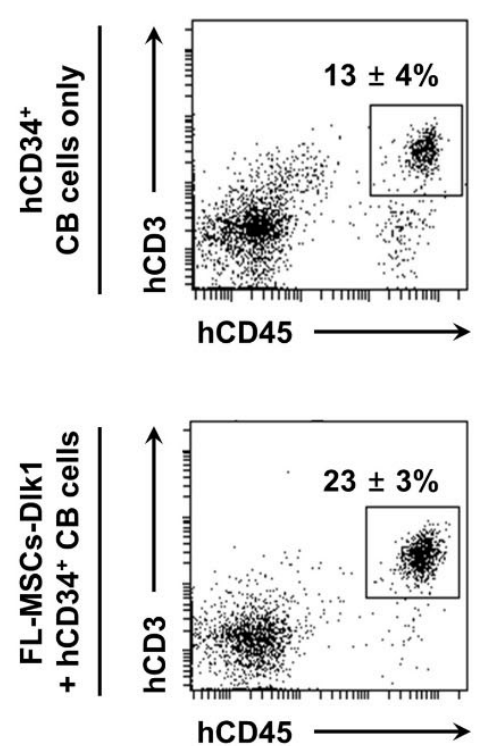

C
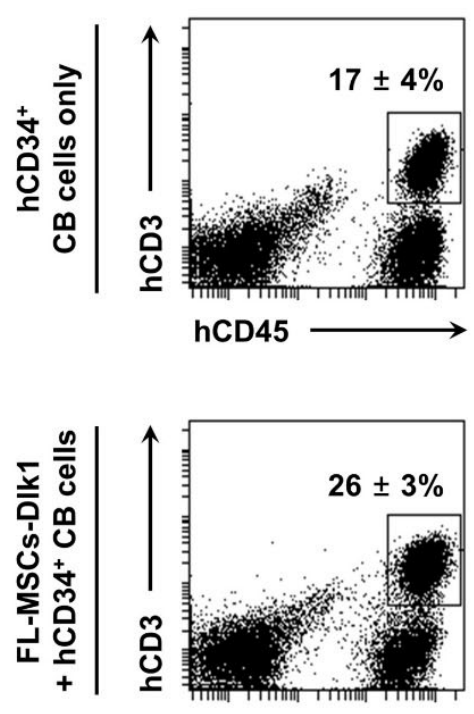

hCD45 d

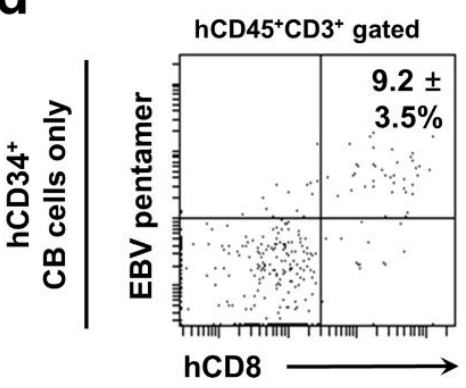

hCD45 ${ }^{+} \mathrm{CD}^{+}$gated

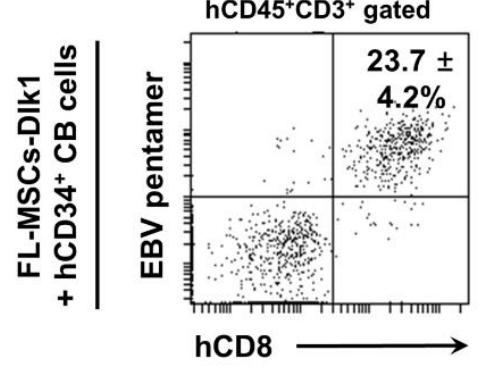

$\square$ hCD34+ CB cells only

$\square$ FL-MSCs-Dlk1 + hCD34+ CB cells

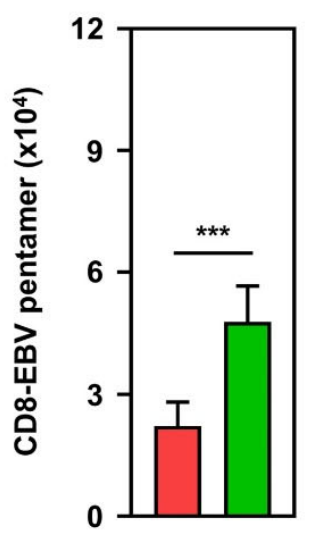

e

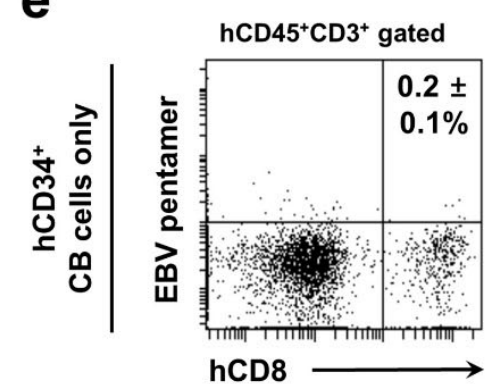

(1)

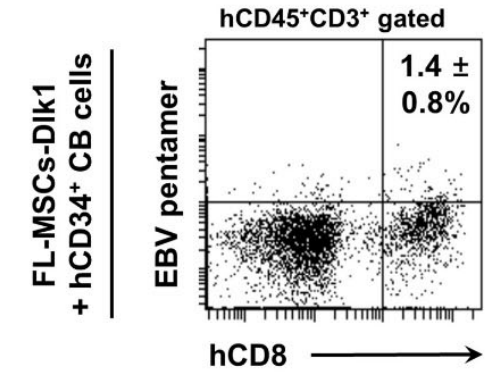

$\square$ hCD34+ $^{+}$CB cells only

$\square$ FL-MSCs-Dlk1 + hCD34 ${ }^{+}$CB cells

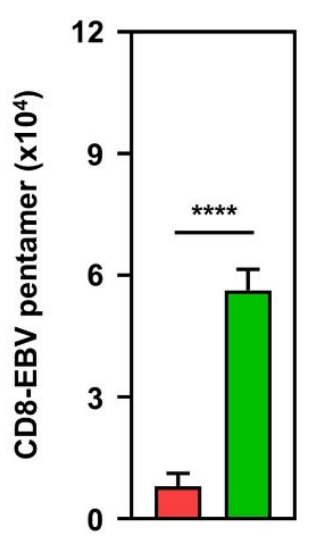

Kwon et al., Figure 6 

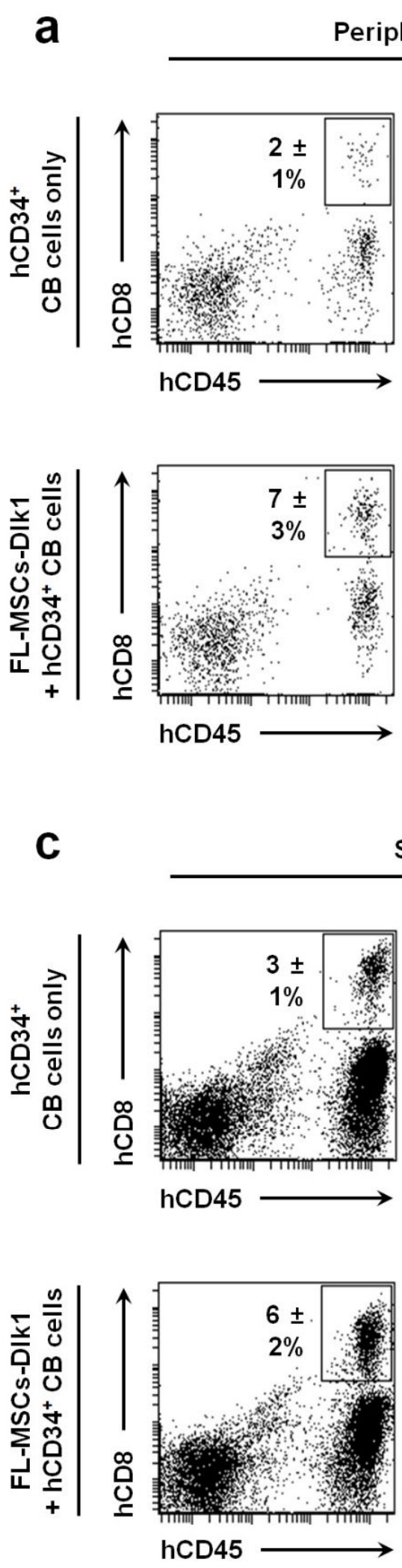

Spleen
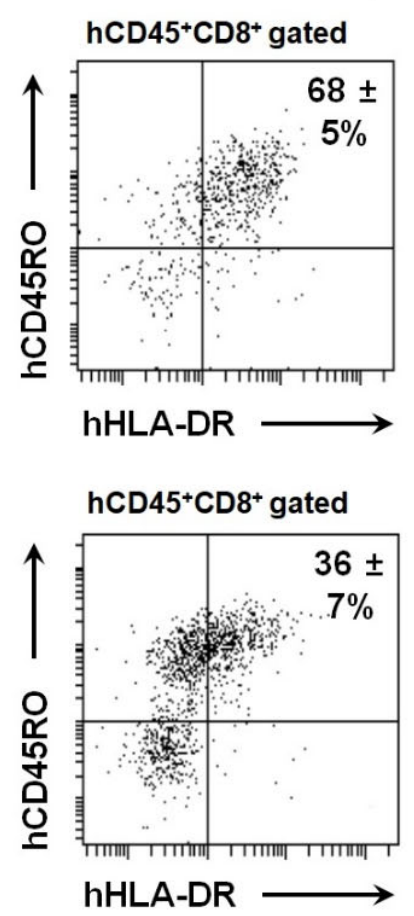

b

hCD34 ${ }^{+} \mathrm{CB}$ cells only

$\square$ FL-MSCs-Dlk1 + hCD34+ CB cells

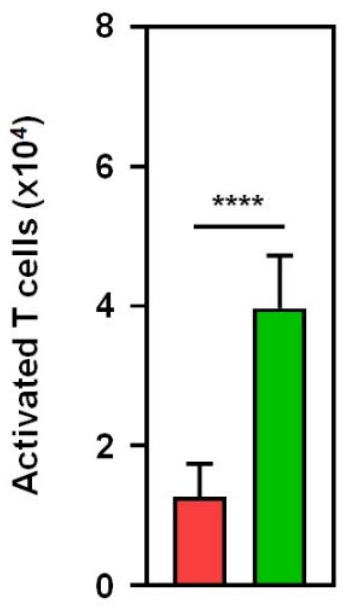

d

hCD34 ${ }^{+}$CB cells only

$\square$ FL-MSCs-DIk1 + hCD34+ CB cells

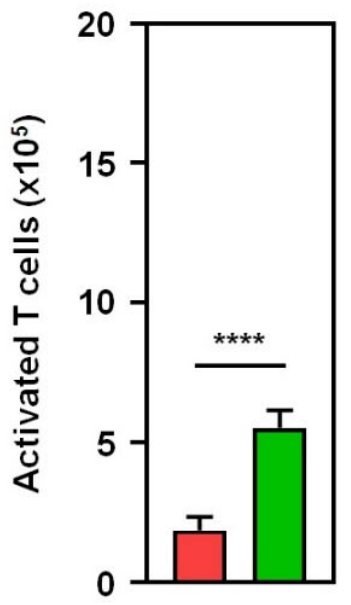




\section{Figures}

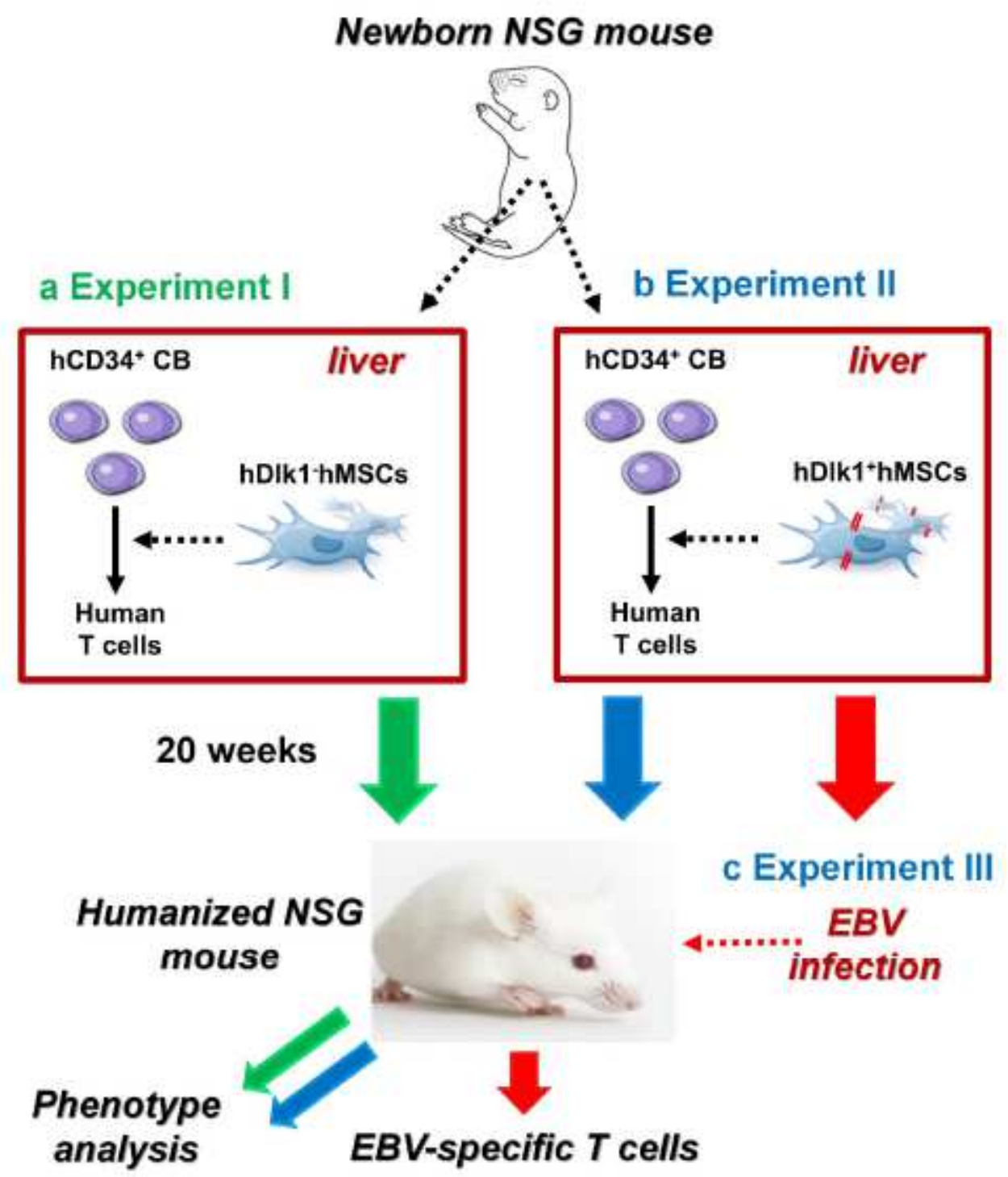

Figure 1

Experimental designs for the generation of humanized NSG mice in this study. Three sets of humanized NSG mice were designed and generated, represented as Experiment I (a, green lines), Experiment II (b, blue lines), and Experiment III (c, red lines) as described in Materials and Methods. (a) Experiment l: hCD34+ CB cells or hCD34+ CB cells plus hMSCs (hDlk-) cells were injected into livers of newborn NSG mice. (b) Experiment II: hCD34+ CB cells or hCD34+ CB cells plus hDlk+hMSCs cells were injected into livers of newborn NSG mice. Reconstitution of human T and B cells was assessed in humanized NSG mice as described in the main text. (c) Experiment III: Humanized NSG mice were generated with hCD34+ CB cells or hCD34+ CB cells plus hDlk+hMSCs cells. After 20 weeks, EBV was used to challenge humanized NSG mice as described in Materials and Methods. 
a

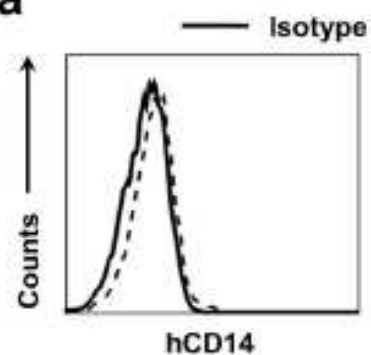

b

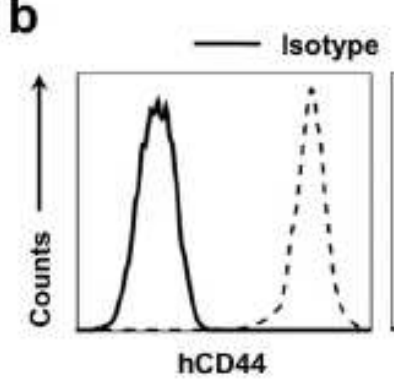

hCD44

d

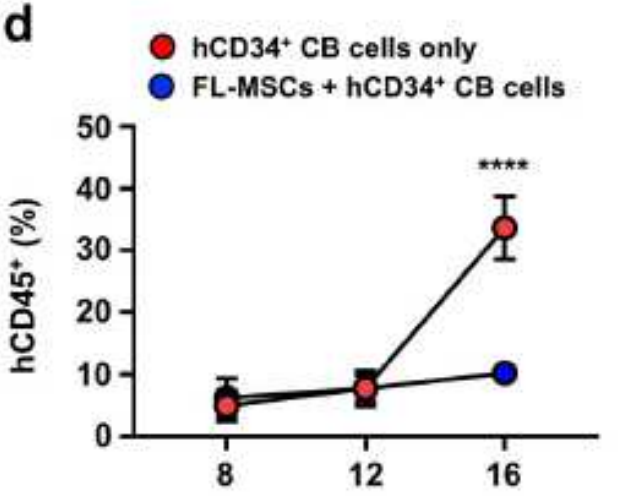

Weeks after injection

FL-MSCs

FL-MSCs

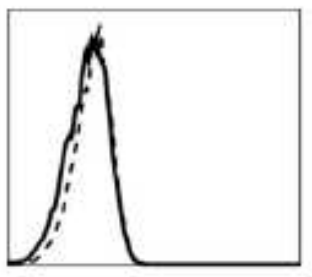

hCD45

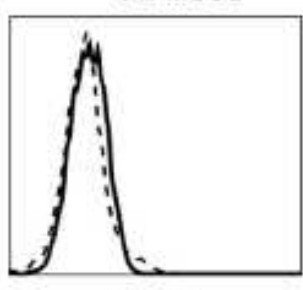

hCD34

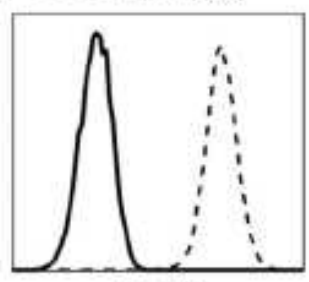

hCD73

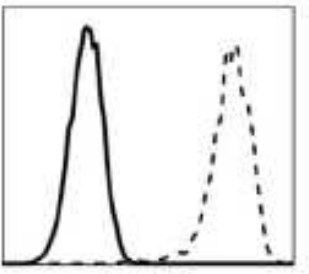

hCD90

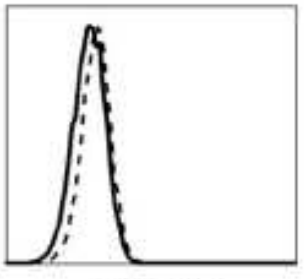

hHLA-DR
C
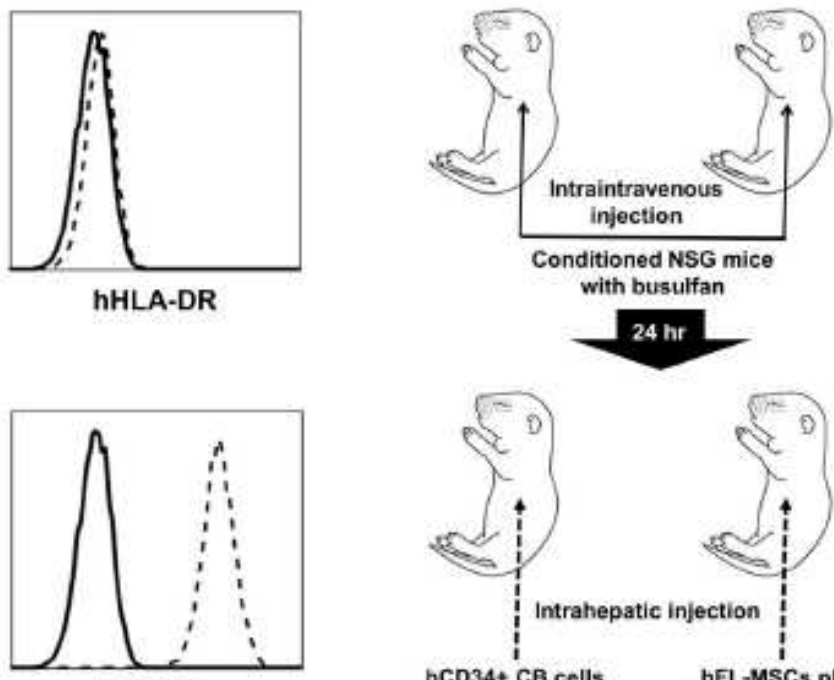

hCD105

e

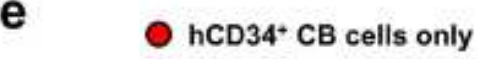
- FL-MSCs + hCD34* CB cells

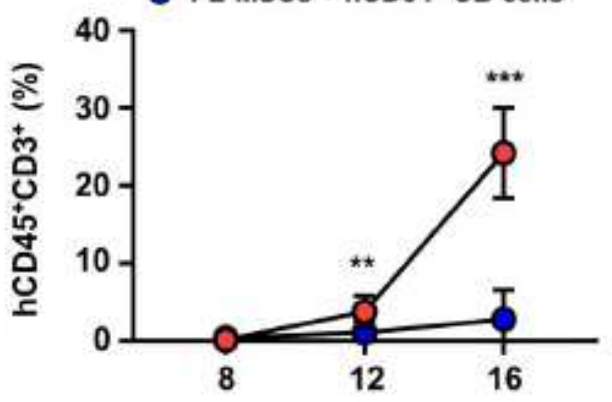

Weeks after injection

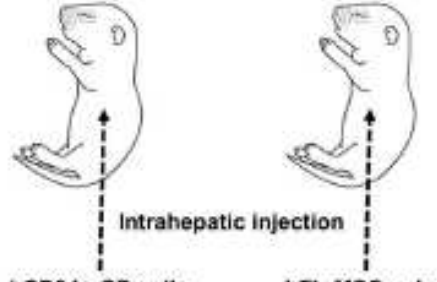

hFL-MSCs plus hCD34+ CB cells

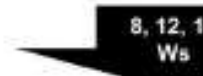

Ws

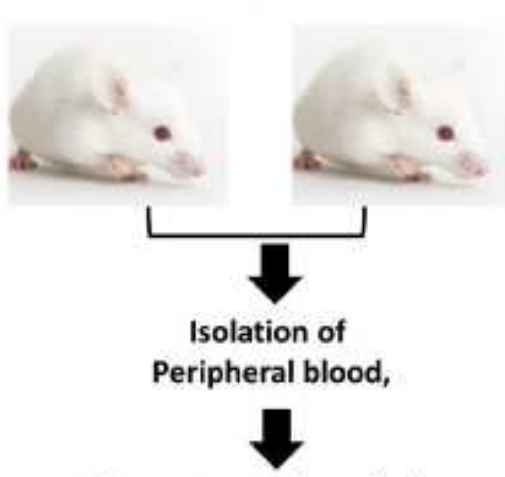

Flow cytometric analysis

Figure 2

Generation of humanized NSG mice engrafted with hCD34+ CB cells together with MSCs. (a and b) Human MSCs were prepared from fetal liver tissues as described in Materials and methods. These cells were stained with anti-CD14, anti-CD34, anti-CD45, anti-HLADR, anti-CD44, anti-CD73, anti-CD90, and antiCD105 antibodies followed by flow cytometry analysis. Isotype antibody in each sample was used as control. (c) Schematic diagram showing the generation of humanized NSG mice. Busulfan was intravenously injected into NSG newborn mice $(n=30)$. After $24 h$, hCD34+CB cells alone $(n=15)$ or together with hFL-MSC cells $(n=15)$ were co-injected into livers of conditioned newborn NSG mice as described in Materials and method. ( $d$ and e) Peripheral blood samples were isolated from humanized NSG mice generated by using hCD34+CB cells alone $(n=5)$ or together with MSCs $(n=5)$ at different time points as indicated. These cells were then stained with anti-hCD 45 and anti-hCD3 antibody followed by flow cytometry analysis on a FACSAria. Ten thousand to 1,000,000 events were acquired per sample and hCD45+ (d) and hCD45+hCD3+ (e) were analyzed using FACSDiva software. Percentages of cells were obtained by manual flow cytometric gating method. Data are shown as the average of five different mice in each group ( \pm S.D). ${ }^{\star}, p<0.05 ; * \star \star, p<0.001 ; * \star \star \star, p<0.0001$. 
a
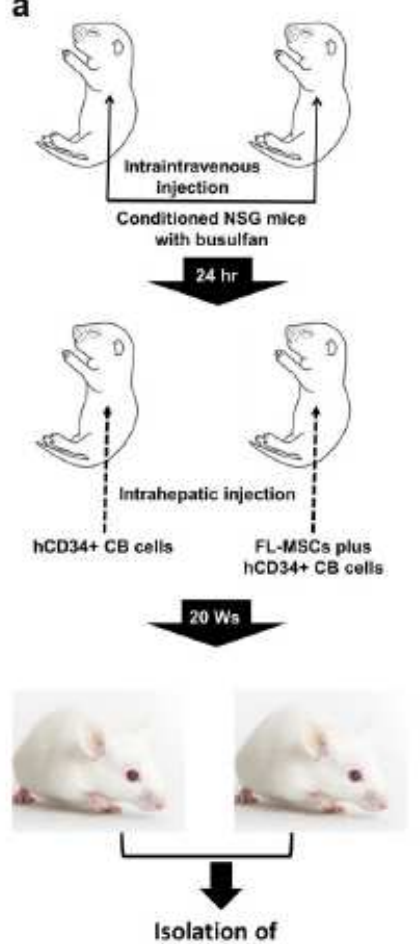

paripheral blood and splean

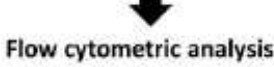

Immunohistochemistry analysis b

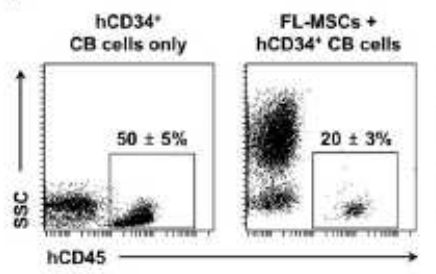

hCD45
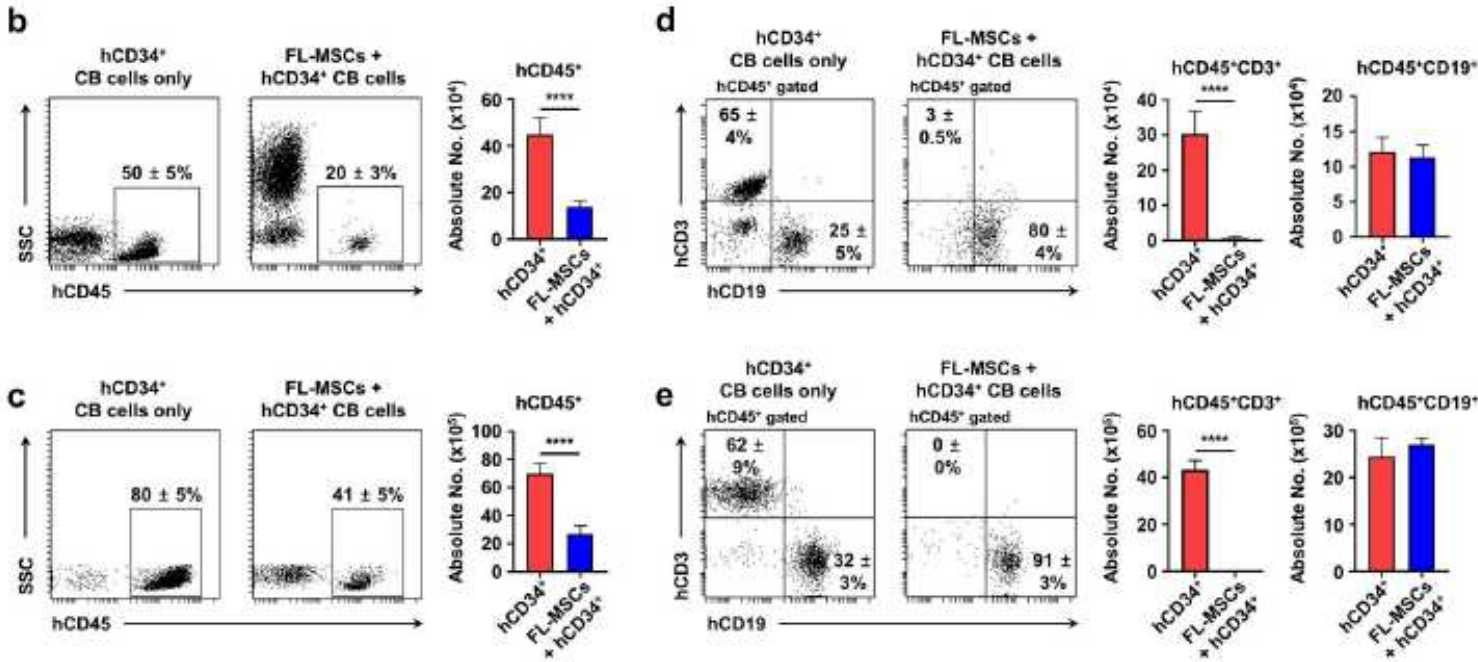
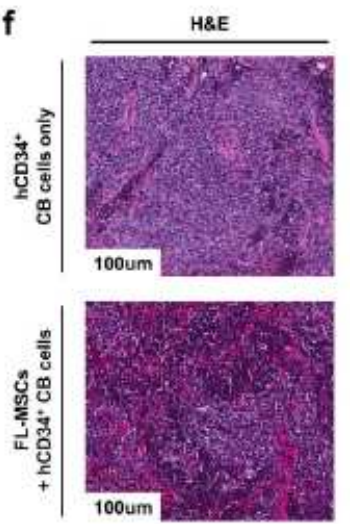

hCO3

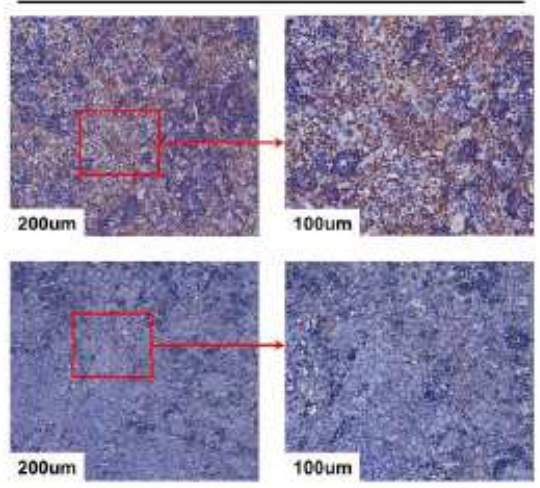

\section{Figure 3}

Human T cell development is suppressed in humanized NSG mice generated with hCD34+ CB cells together with h-FL-MSCs. (a) Schematic diagram showing the generation of humanized NSG mice. Busulfan was intravenously injected into NSG newborn mice $(n=30)$. After $24 h$, hCD34+CB cells alone $(n=15)$ or together with hFL-MSC cells $(n=15)$ were co-injected into livers of conditioned newborn NSG mice as described in Materials and Methods. (b-e) Peripheral blood (b and d) and spleen (c and e) tissues samples were isolated from humanized NSG mice generated with hCD34+ CB cells alone $(n=8)$ or together with hFL-MSCs $(n=8)$. These cells were stained with anti-hCD45, anti-hCD3, and anti-hCD19 antibodies as described in Materials and methods. Percentages and absolute numbers of cells were obtained by manual flow cytometric gating and counted. Data are presented as the average of eight different mice in each group ( \pm S.D). ${ }^{\star \star \star \star}, p<0.0001$. (f) Spleens were isolated from humanized NSG mice, fixed with $10 \%$ formalin, and embedded in paraffin. Paraffin embedded tissue sections were stained with hematoxylin and eosin (H\&E) and anti-hCD3 antibody as described in Materials and Methods. Stained slides were observed using an Olympus BX40 light microscope. Photographs were taken with a microscope digital camera DP50 and analyzed with an Image-pro plus 5.1 software. 
a

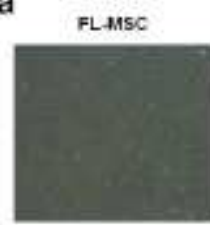

oaplots
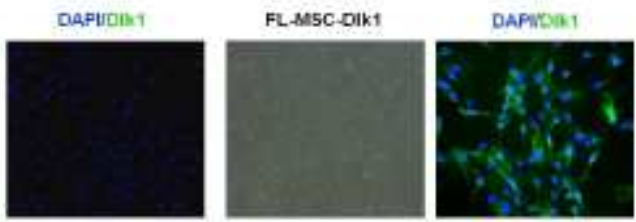

b

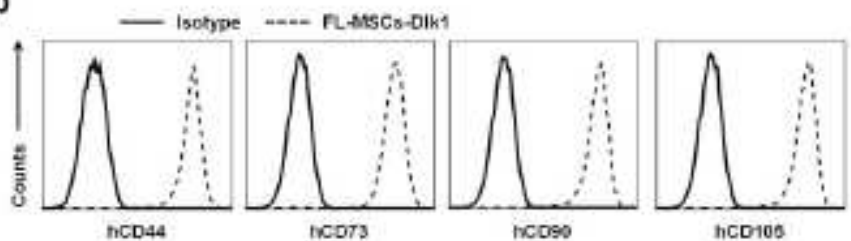

c

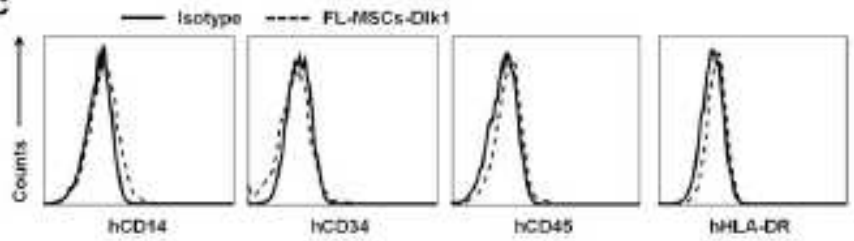

d

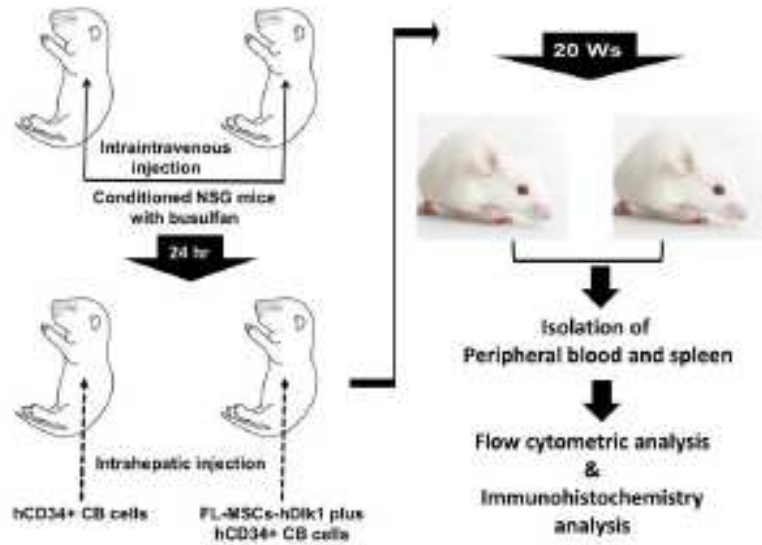

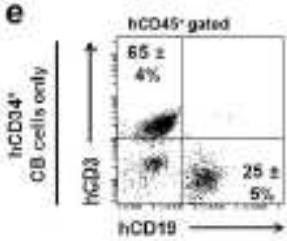

heous usted
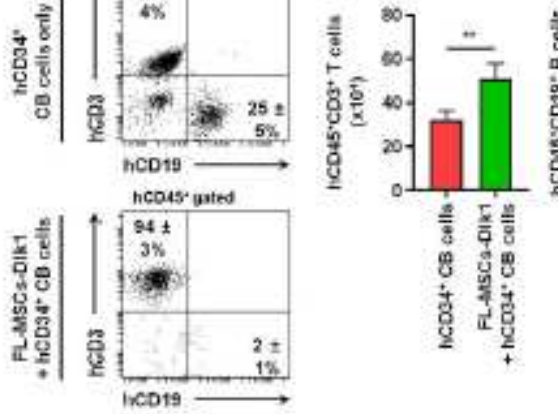

敦言言

总列思

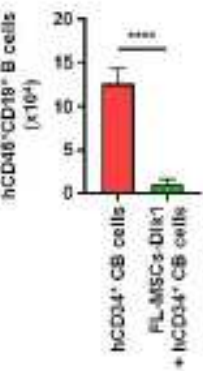

f
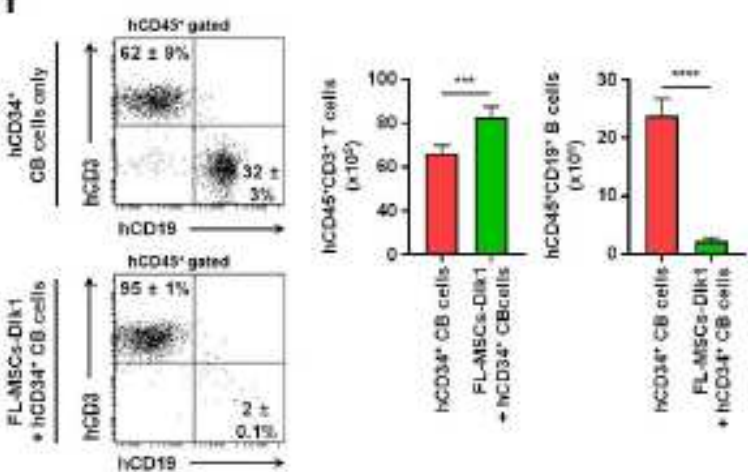

g
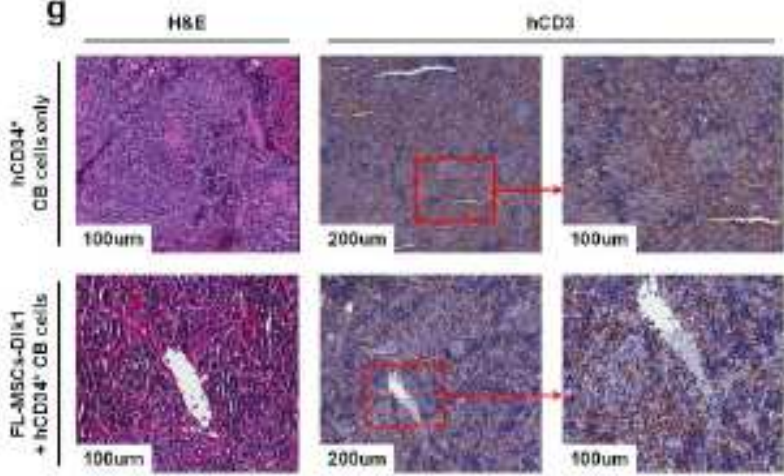

\section{Figure 4}

Generation of humanized NSG mice engrafted with hCD34+ CB cells together with human delta-like 1 (hDlk1)-expressing MSCs. (a) Human FL- MSCs were incubated with viruses at a multiplicity of infection (MOI) of 10 or 15 in FL-MSCs culture medium containing $8 \mu \mathrm{g} / \mathrm{ml}$ polybrene. These transduced cells were selected for two weeks as described in Materials and Methods. Immunofluorescence staining was performed for hFL-MSC or hDlk1-expressing hFLMSC cells as described in Materials and Methods. Stained slides were observed using an Olympus BX51 fluorescence microscope. Photographs were taken with a microscope digital camera DP50 and analyzed using an Image-pro plus 5.1 software. (b and c) hDlk1- expressing hFL-MSC cells were stained with anti-CD14, anti-CD34, anti-CD45, anti- HLA-DR, antiCD44, anti-CD73, anti-CD90, and anti-CD105 antibodies followed by flow cytometry analysis. Isotype antibody in each sample was used as control. (d) Schematic diagram showing the generation of humanized NSG mice. Busulfan was intravenously injected into NSG newborn mice $(n=30)$. After 24 h, hCD34+ CB cells alone $(n=15)$ or together with hFL-MSC-hDIk1 cells $(n=15)$ were co-injected into livers of conditioned newborn NSG mice as described in Materials and method. (e and f) Peripheral blood (e) 
and spleen ( $f$ ) tissues samples were isolated from humanized NSG mice generated with hCD34+ CB cells alone $(n=8)$ or together with hFL-MSCs-hDIk $(n=8)$. Cells were stained with anti-hCD45, anti-hCD3, and anti-hCD19 antibodies as described in Materials and methods. Percentages and absolute numbers of cells were obtained by manual flow cytometric gating and counted. Data are presented as average values of eight different mice in each group ( \pm S.D). $* *, p<0.01$; $* \star \star, p<0.001 ; * \star \star \star, p<0.0001$. (g) Spleens were isolated from humanized NSG mice, fixed in $10 \%$ formalin, and embedded in paraffin. Paraffin embedded tissue sections were stained for hematoxylin and eosin (H\&E) and anti-hCD3 antibody as described in Materials and Methods. Stained slides were observed using an Olympus BX40 light microscope.

Photographs were taken with a microscope digital camera DP50 and analyzed with an Image-pro plus 5.1 software.

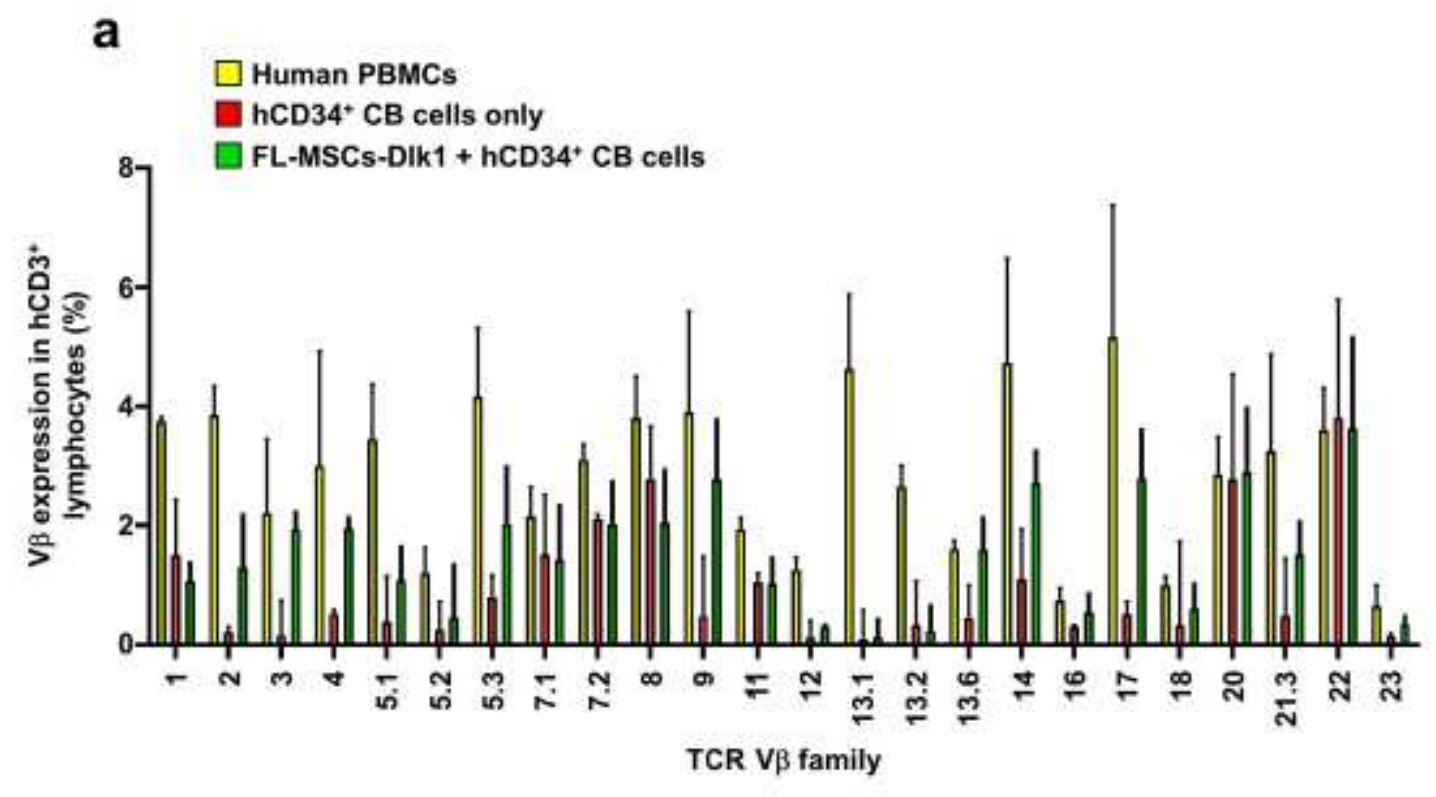

b

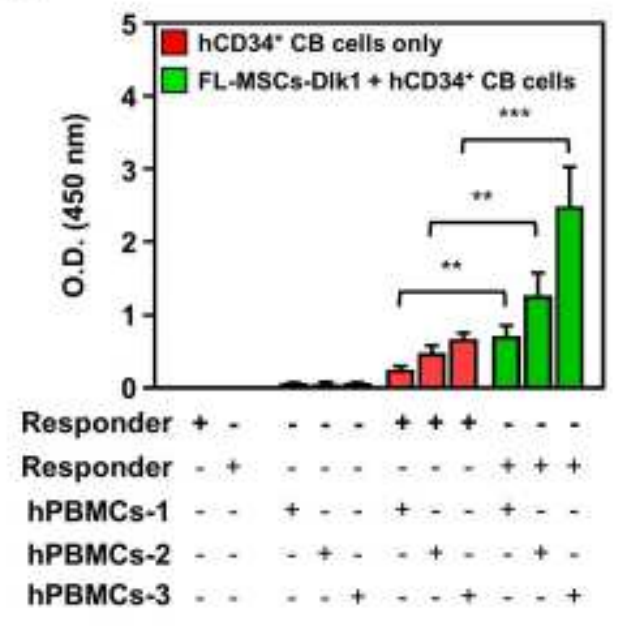

C

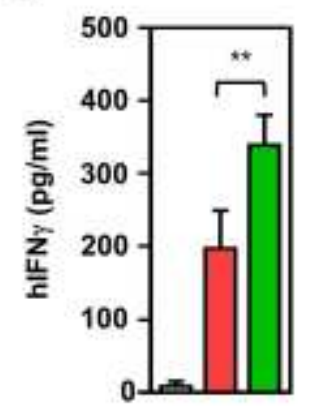

d

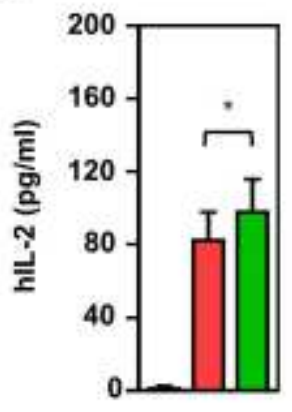

$\square$ Responder only

hCD34* CB cells only

FL-MSCs-DIk1 + hCD34* CB cells

Figure 5

Characterization of humanized mice generated with hDlk1-expressing FLMSCs and hCD34+ CB cells. (a) Peripheral blood samples were isolated from humanized mice generated with hCD34+CB cells alone $(\mathrm{n}=$ $5)$ or together with hDlk1-expresing MSC cells $(n=5)$ as described in Fig. 4D. Single cells were prepared 
as described in Materials and Methods. These cells were stained with a TCR V $\beta$ repertoire kit according to the manufacturer's instructions. PBMCs were also isolated from normal healthy volunteers $(n=3)$ and stained with the TCR V $\beta$ repertoire kit. Samples were analyzed using a FACSAria. Data are presented as the average of triplicate samples $( \pm$ S.D). (b) Human CD3+ lymphocytes as responder cells were isolated from spleens of humanized NSG mice and then used for MLR assay as described in Materials and methods. Data are presented as the average of triplicate samples $( \pm S . D) .{ }^{*}, p<0.05 .{ }^{\star \star}, p<0.01 ; * \star \star, p<$ 0.001. ( $c$ and d) Purified human $C D 3+T$ cells were co-cultured in the presence or absence of irradiated PBMCs isolated from healthy human volunteers as described in Materials and methods. After 3 days, supernatants were harvested and levels of human cytokines such as hIFN-y (c) and hIL-2 (d) were measured with ELISA Kits according to the manufacture's instruction. Data are presented as the average of triplicate samples ( \pm S.D). ${ }^{*}, p<0.05 ; * *, p<0.01$.

a
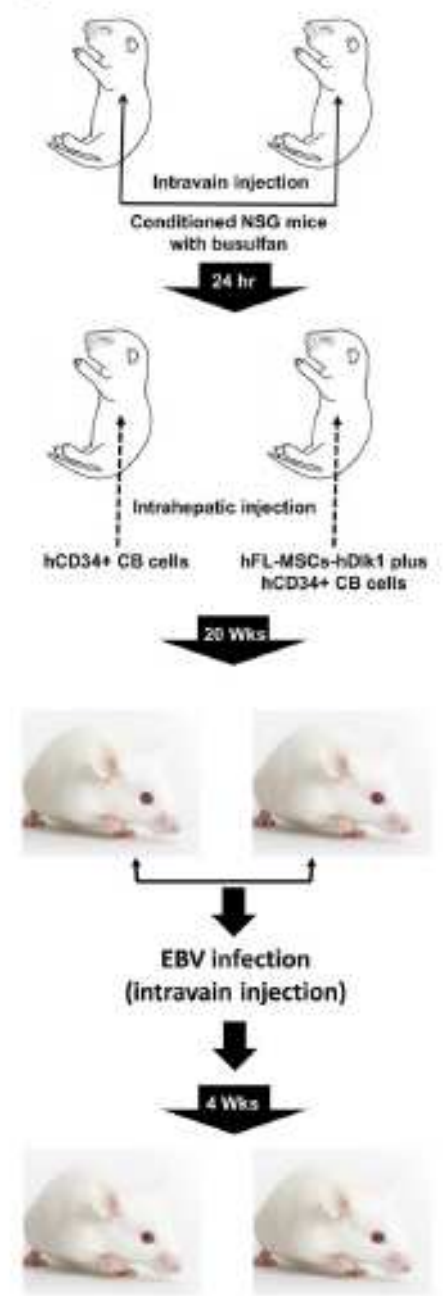

Killed, isolated peripheral blood and spleen, and flow cytometric analysis b
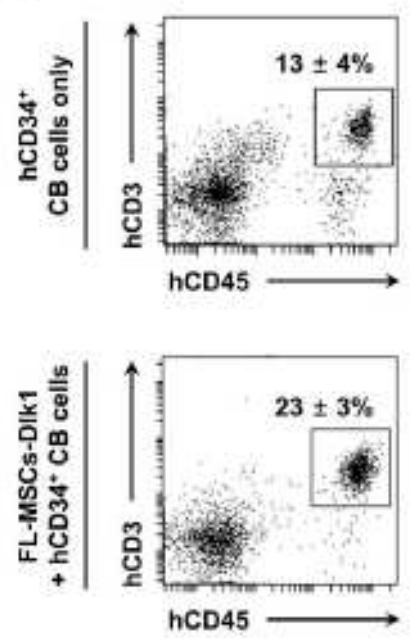

C
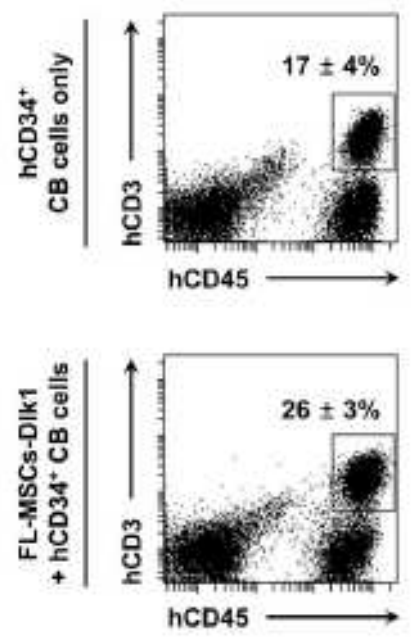

d

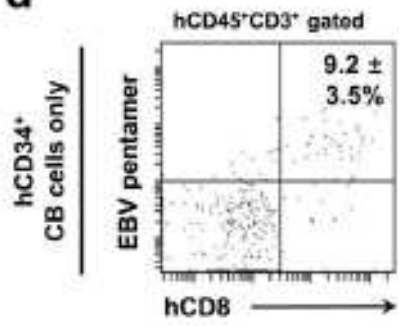

hCD45'CD3* gated

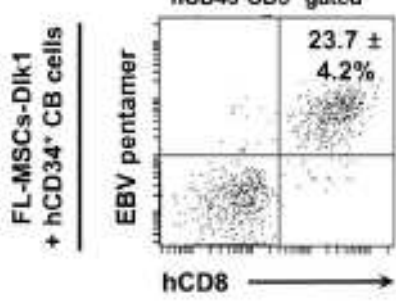

e
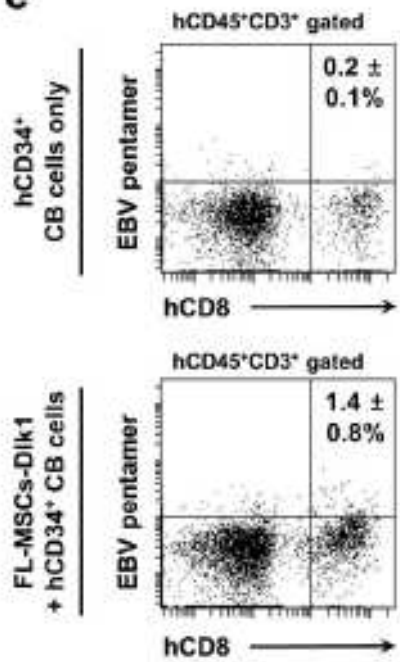

hCD $34^{+} \mathrm{CB}$ cells only

I FL-MSCs-Dlk1 + hCD34* CB cells

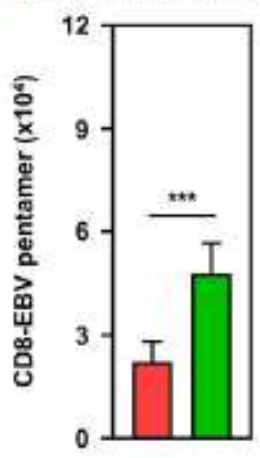

hCD $34^{+} \mathrm{CB}$ cells only

FL-MSCs-DIk1 + hCD34+ CB cells

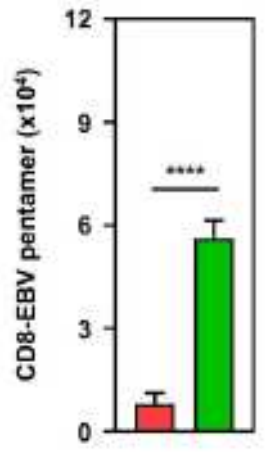

\section{Figure 6}

EBV infection induces the generation of EBV-specific T cells in humanized NSG mice generated with hDlk1-expressing hFL-MSCs. (a) A protocol for performing EBV infection. Humanized NSG mice were 
generated with hCD34+CB cells alone $(n=10)$ or together with hDlk1-expressing hFL-MSCs $(n=10)$ as described in Materials and methods. After 20 weeks, EBVs were injected to humanized mice via intravenous infection as described in Materials and Methods. (b and c) At 4 weeks after EBV infection, peripheral blood (b) and spleen tissue (c) samples were isolated from humanized mice generated with hCD34+CB cells alone $(n=5)$ or together with hDlk1-expressing hFL-MSCs $(n=5)$. Cells were prepared as described in Materials and Methods and stained with anti-hCD45 and hCD3 antibodies. Percentages of cells were obtained by manual flow cytometric gating method. Data are presented as the average of triplicate samples ( \pm S.D). ( $d$ and e) PBMCs $(d, n=5)$ and spleen $(e, n=5)$ were isolated from humanized NSG mice. Cells stained with anti-hCD45, anti-hCD3, anti-hCD8, and anti-EBV pentamer as described in Materials and methods. Percentages and absolute numbers of cells were obtained by manual flow cytometric gating and counted. Data are presented as the average of triplicate samples ( \pm S.D). $* \star \star, p<$ $0.001 ; * * * *, p<0.0001$.

a
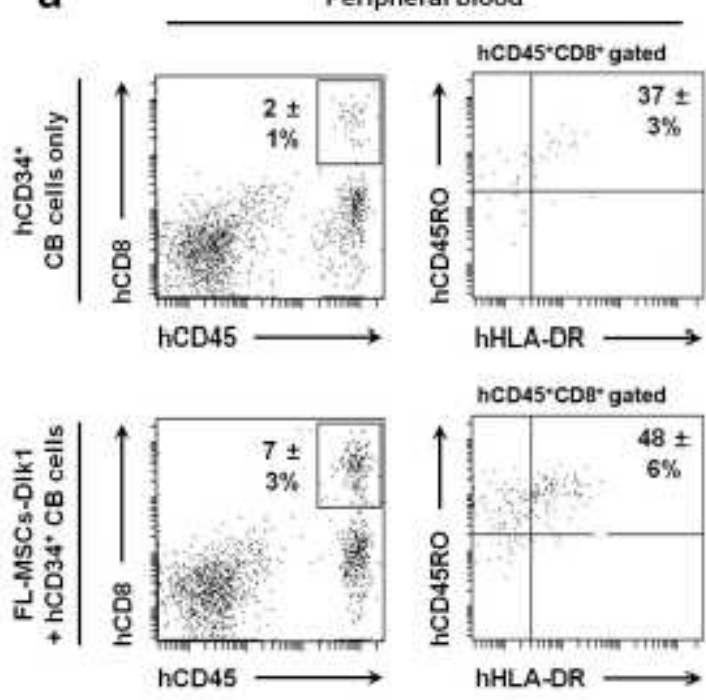

C

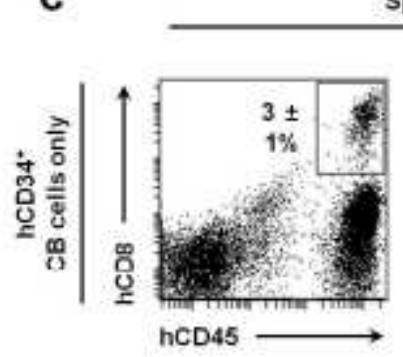

Spleen
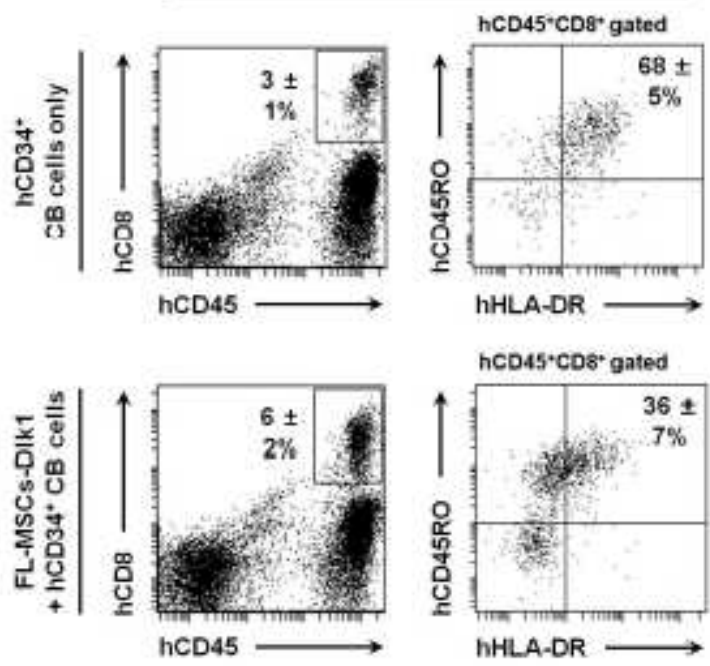

b

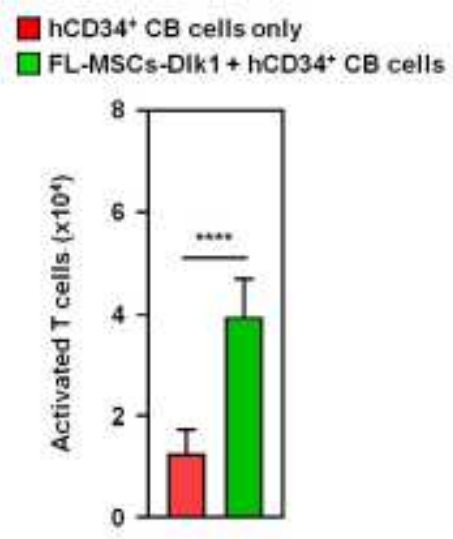

d

$\square$ hCD34* CB cells only

$\square$ FL-MSCs-DIk1 $+h \mathrm{hD} 34^{+} \mathrm{CB}$ cells

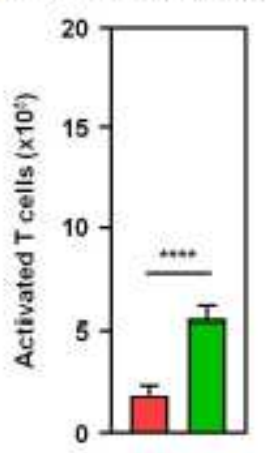

Figure 7 
Activated T cells are elevated in humanized NSG mice generated with hDlk1- expressing hFL-MSCs. (a and b) At 4 weeks after EBV infection, peripheral bloods were isolated from humanized mice generated with hCD34+CB cells alone $(n=5)$ or together with hDlk1- expressing hFL-MSCs $(n=5)$. Cells were prepared as described in Materials and methods and stained with anti-hCD45, hCD3, hCD8, hCD45RO, and hHLA-DR antibodies. Percentages (a) and absolute numbers (b) of cells were obtained by manual

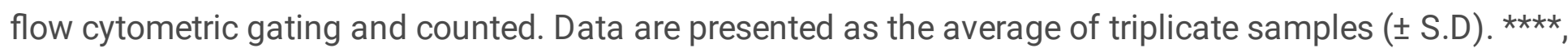
$p<0.0001$. (c and d) At 4 weeks after EBV infection, spleen tissues were isolated from humanized mice generated with hCD34+CB cells alone $(n=5)$ or together with hDlk1-expressing hFL-MSCs $(n=5)$. Cells are prepared, as described in Materials and methods and stained with anti-hCD45, hCD3, hCD8, hCD45RO, and hHLA-DR antibodies. Percentages (c) and absolute numbers (d) of cells were obtained by manual

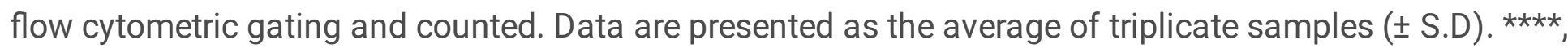
$\mathrm{p}<0.0001$.

\section{Supplementary Files}

This is a list of supplementary files associated with this preprint. Click to download.

- SupplementaryInformation.docx 